\title{
EL DEPÓSITO DE YUNCLILLOS (TOLEDO) Y LOS DEPÓSITOS DE HACHAS PLANAS EN LA PENÍNSULA IBÉRICA: UNA PROPUESTA CRONOLÓGICA
}

\author{
THE YUNCLILLOS HOARD (TOLEDO) AND THE FLAT AXES HOARDS IN \\ THE IBERIAN PENINSULA: A CHRONOLOGICAL FRAMEWORK
}

\author{
ARTURO RUIZ-TABOADA \\ Departamento de Prehistoria, Historia Antigua y Arqueología. Facultad de Geografía e Historia de la Universidad Complutense de Madrid. \\ C/ Profesor Aranguren, s/n, Edificio B, Ciudad Universitaria, 28040 Madrid. Correo-e.: arruiz01@ucm.es \\ (D) https://orcid.org/0000-0002-7957-2954 \\ JUAN PEREIRA SIESO \\ Facultad de Humanidades de Toledo. Plaza de Padilla no 4. 45071 Toledo. Correo-e.: Juan.Pereira@uclm.es \\ (D) https://orcid.org/0000-0003-1266-5360 \\ ANTONIO URIARTE GONZÁLEZ \\ Laboratorios de I+D de Arqueología: Laboratorio arqueología del paisaje y teledetección. Instituto de Historia. CSIC. C/Albasanz 26-28. \\ 28071 Madrid. Correo-e.: antonio.uriarte@cchs.csic.es (i) https://orcid.org/0000-0001-9165-957X \\ MERCEDES MURILLO-BARROSO \\ Departamento de Prehistoria y Arqueología. Facultad de Filosofía y Letras. Universidad de Granada. Campus de Cartuja s/n. \\ 18071 Granada. Correo-e.: murillobarroso@ugr.es (I) https://orcid.org/0000-0002-2271-291X \\ M. ISABEL MARTÍNEZ-NAVARRETE \\ Departamento de Arqueología y procesos sociales. Instituto de Historia. CSIC. C/Albasanz 26-28. 28071 Madrid. \\ Correo-e.: isabel.martinez@cchs.csic.es (iD https://orcid.org/0000-0002-3060-6033 \\ IGNACIO MONTERO-RUIZ \\ Departamento de Arqueología y procesos sociales. Instituto de Historia. CSIC. C/Albasanz 26-28. 28071 Madrid. \\ Correo-e.: ignacio.montero@cchs.csic.es (D) https://orcid.org/0000-0003-0897-1031
}

Resumen: La aparición en escena de un nuevo depósito compuesto por siete hachas planas en Yunclillos (Toledo) permite ampliar la escasa muestra de un tipo peculiar de utensilio, caracterizado por su gran tamaño y por su reducido perfil. Se analiza el fenómeno de los depósitos de hachas planas en la península ibérica y pese a la ausencia de un contexto arqueológico de referencia, la tipología y la composición elemental parecen indicar que los depósitos pueden corresponder a un momento inicial de la Edad del Bronce.

Palabras clave: Edad del Bronce; península ibérica; depósitos de hachas planas; metalurgia; tecnología; metalografía; composición elemental.

\begin{abstract}
A new hoard with 7 flat axes found in Yunclillos (Toledo) offers a new perspective about a specific type of axe characterized by its long size and thin section. A reflection about flat axes hoarding in the Iberian Peninsula, most of them without archaeological context, let us propose an Early Bronze Age Chronology based on typological criteria and elemental composition.
\end{abstract}

Keywords: Bronze Age; Iberian Peninsula; Flat Axes Hoards; Metallurgy; Technology; Metallography; Elemental composition. 


\section{INTRODUCCIÓN}

La deposición de metales es un fenómeno característico de la Edad del Bronce en Europa que tiene su apogeo durante el Bronce Final. Estas prácticas de tesaurización, iniciadas en periodos anteriores, no tienen en la península ibérica la relevancia (Brandherm 2007) que en otros territorios como la Europa central. Allí durante el Bronce Antiguo y Medio aparecen depósitos que contienen desde varias decenas de herramientas, armas y adornos hasta, a veces, más de un centenar de objetos y $30 \mathrm{~kg}$ de peso (Harding 2003). En la península ibérica la escala de deposición de metales en estos inicios de la Edad del Bronce es más reducida y en el caso de las armas es excepcional superar la decena de piezas (Branherm 2007: 181). Los depósitos de hachas planas, sin embargo, rompen esa tendencia y además acumulan una mayor cantidad de metal debido al mayor peso de cada pieza. El de Asiego (Asturias) tiene entre catorce-dieciséis ejemplares (Blas 1999: 51) y siete el de Torreorgaz (Cáceres); han sido poco valorados en la bibliografía el depósito de Valchica, también conocido como de Ejea de los Caballeros (Zaragoza), que podría haber alcanzado veinte hachas y el de Cañada de las Cañas (Pozuelo de Calatrava, Ciudad Real) conocido como Campo de Calatrava, con trece ejemplares (Monteagudo 1977; Brandherm 2007). El volumen de metal acumulado en estos depósitos excede con mucho el recuperado en poblados y enterramientos de sus entornos geográficos.

Todos estos depósitos cuentan con una sola categoría de objeto, que se describe genéricamente como hacha plana con dos variantes diferenciables. Una, representada en los depósitos de Valchica y Campo de Calatrava, comprende hachas con espesor proporcionalmente fino (menos de $10 \mathrm{~mm}$ ), superan los $22 \mathrm{~cm}$ de longitud y son relativamente más anchas (la anchura máxima del filo supera los $10 \mathrm{~cm}$ ). Cada hacha suele pesar en torno al kilo. Monteagudo (1977) las clasificó en los grupos 5D y $5 \mathrm{E}$. Desde su recopilación han aparecido el depósito de Estepa (Sevilla) y ahora el de Yunclillos (Toledo), al que dedicaremos una parte de este trabajo. Otros ejemplares similares son el de Seurre y los dos de Mondouzil en Francia (Klassen et al. 2007), el hacha de Mieres (Monteagudo 1977) y dos encontradas en Cerrocuquillo (Toledo) (Baquedano et al. 2010) (fig. 1).

La segunda variante de hachas planas integra los depósitos de Asiego (Asturias) y Torreorgaz (Cáceres). Está encuadrada en el tipo 2B4 de Monteagudo (1977). Su longitud máxima es inferior a las del grupo anterior, aunque siempre supera los $15 \mathrm{~cm}$, y ejemplares como los de Torreorgaz se aproximan a los $20 \mathrm{~cm}$. Sobre todo son hachas más estrechas $(<8 \mathrm{~cm})$ y más gruesas $(>10 \mathrm{~mm}$ ), cuyo peso también suele superar el kilogramo. Este tipo de hacha de grandes dimensiones también se identifica en ejemplares sueltos que no forman depósitos, clasificables tanto en el mencionado grupo 2B4 como en los grupos 5A, B y C de Monteagudo.

Dentro de este fenómeno de deposición de hachas, un caso singular sería el depósito de Espite (Vila Nova de Ourem, Portugal). Combina hachas de distintos tamaños, completas y rotas, algunas con dimensiones grandes según las estimaciones del propio Monteagudo (1977), pero ninguna con las proporciones del grupo de las hachas planas anchas.

Destacamos que el tipo de hacha plana ancha y fina que centra el interés de este trabajo suele aparecer formando depósitos que contienen un número elevado de piezas, pero por desgracia sin contextos arqueológicos claros, ni elementos materiales asociados que ayudaran a su encuadre cronológico preciso, como ocurre en el nuevo depósito de Yunclillos. Como es habitual en el material prehistórico, pueden detectarse variantes según se atienda al perfil, al desarrollo de los filos, o a la presencia de ligeros rebordes en algunos ejemplares.

Para entender este fenómeno de deposición y acumulación de metal anterior al Bronce Final y valorar su funcionalidad, primero debemos tratar de encuadrarlo cronológicamente con mayor detalle, ya que las propuestas realizadas abarcan desde el Calcolítico precampaniforme (Bradherm 2007: 182) hasta el Bronce Final orientalizante (Fernández Gómez 2003). Ante la falta de contexto arqueológico o material asociado, la composición de los metales, su distribución geográfica y la revisión de la información asociada en los nuevos hallazgos, así como su ocultamiento formando depósitos homogéneos, añaden elementos al análisis del fenómeno y facilitan las referencias para tratar de ajustar la cronología de la deposición de hachas planas en general. Somos conscientes de que el tema incluye varios debates, entre ellos el de la funcionalidad de las piezas (ya se consideren herramientas o posibles lingotes) cuya argumentación es clave para entender el propio fenómeno de deposición. Las limitaciones de espacio para poder desarrollar esos otros aspectos nos han llevado primero a intentar clarificar la cuestión cronológica.

\section{EL DEPÓSITO DE YUNCLILLOS (TOLEDO)}

Conocimos este depósito por casualidad. Gracias a las gestiones de una estudiante de la Facultad de 


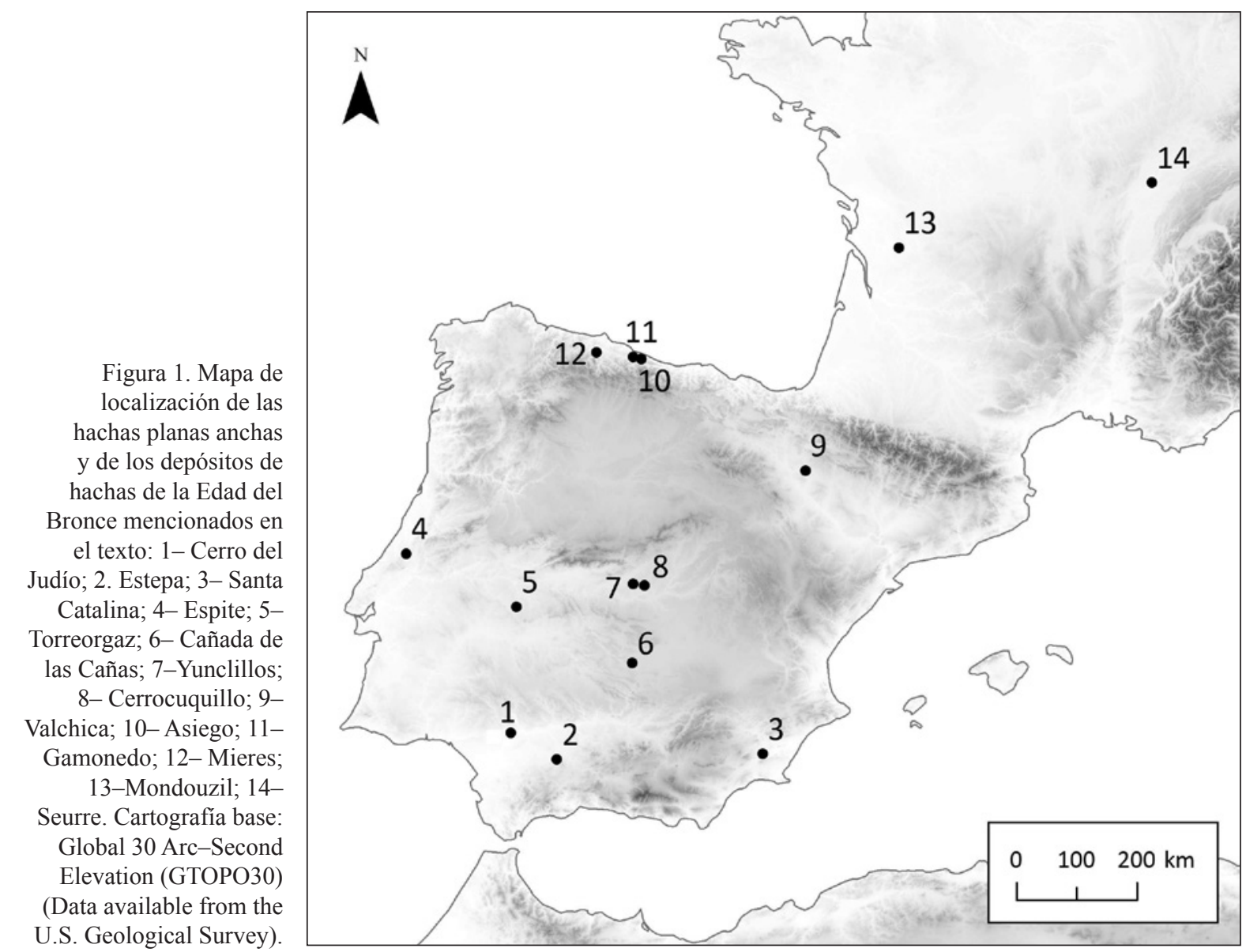

Humanidades de Toledo (UCLM), uno de los profesores (JP) pudo acceder a una peculiar herencia familiar: siete hachas planas (fig. 2). Como ocurre en estos casos, el protagonista desconocía su procedencia. La tradición agrícola de su familia permitía intuir cómo ocurrió el descubrimiento. La posterior prospección arqueológica del entorno donde el informante lo situaba resultó negativa. Pese a que la procedencia de las piezas es imprecisa, al menos es posible asegurar que se corresponde con terrenos propiedad de la familia en esa misma zona y por las noticias de los herederos de su descubridor, parece que formaban un conjunto homogéneo.

Esta zona del valle del Guadarrama es rica en hallazgos metálicos, como la alabarda de Villamiel (Ruiz Taboada y Montero 2000) encontrada a menos de 10 $\mathrm{km}$ en línea recta del depósito de Yunclillos o las hachas de Cerro Cuquillo (fig. 1, nº 7 y 8), también dentro de ese radio de $10 \mathrm{~km}$ de distancia y que comentaremos más adelante. Varios sitios calcolíticos y de la Edad del Bronce son conocidos en los términos municipales de
Bargas y Yunclillos, pero el yacimiento más cercano se encuentra en la misma margen del río y lo identificamos en las prospecciones realizadas en el vecino término municipal de Bargas (Uriarte et al. 2011), en el espigón de confluencia del río Guadarrama con un barranco-torrente (yacimiento de Tributillos, Carta arqueológica de Castilla La Mancha, código de referencia, 07450190001), a una distancia de $750 \mathrm{~m}$ al sur de la supuesta localización del depósito (fig. 3). El sitio cuenta con fragmentos de cerámica a mano que solo permiten un encuadre impreciso en el Calcolítico o la Edad de Bronce y también aparece abundante material romano.

La homogeneidad tipológica del conjunto y la simultaneidad de su depósito vienen corroboradas por la impronta de una oxidación diferencial en la superficie de las hachas 2, 3, 4 y 7 . Esa impronta indica que las siete debieron colocarse alternando los filos para formar un bloque, destinado a facilitar el transporte o almacenaje (fig. 4). El hacha 3, la más larga, definía su longitud, mientras las hachas 2 y 7 , las de mayores filos, fijaban la anchura 


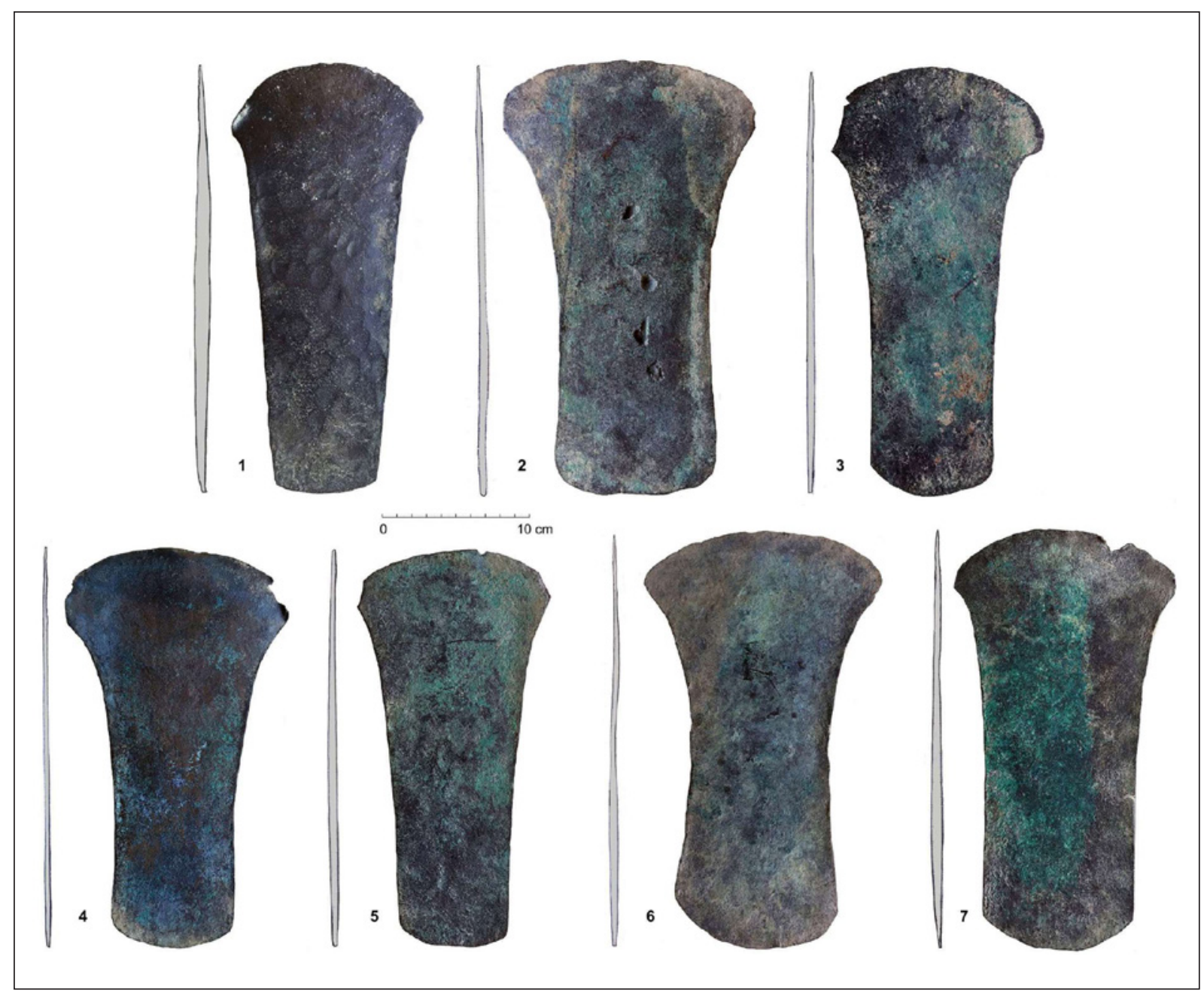

Figura 2. Hachas del depósito de Yunclillos con los números de identificación empleados en el texto (fotografía Oscar García Vuelta).

superior e inferior del paquete. La amplia escotadura central recibiría la cinta de cuero u otro material que fijaría el conjunto. Algunas piezas presentan daños en los filos y algunas partes perdidas. Carecemos de criterio para decidir si ya existían antes de hallar el depósito.

El hacha $n^{\circ} 1$ se diferencia mucho del resto por su forma trapecial más nítida con los bordes laterales rectos, propia de las típicas hachas planas. Los contornos de las demás son más sinuosos. Los bordes de algunas son claramente divergentes tanto en el filo como en el talón (fig. 5). En conjunto estas hachas son de las más grandes hasta ahora documentadas en la península ibérica (los datos morfométricos se recopilan en la tabla 1), siendo su longitud entre 27 y $31 \mathrm{~cm}$. Solo las supera el hacha 3 de la calle Trabajadores de Valencina de la Concepción con sus 34,9 cm de largo (López Aldana y Pajuelo Pando 2013).
Otro rasgo que individualiza el hacha $\mathrm{n}^{\circ} 1$ es la presencia clara de probables huellas de martillado tanto en el anverso como en el reverso de la pieza. Se puede hasta identificar las características de la cabeza del martillo utilizado. La superficie sería roma, ligeramente convexa, con un diámetro aproximado de $2 \mathrm{~cm}$ (fig. 5). Las improntas, pese a ser planas, presentan una cierta curvatura en su reborde, identificándose impactos planos (circulares) y ligeramente oblicuos (ovalados). Una impronta oval similar se ha detectado en el hacha $n^{\circ}$ 5. No es descartable que la misma herramienta se empleara puntualmente en las demás.

La composición de las hachas de Yunclillos es de cobre o cobre arsenicado (As entre 0,18 y 2,7\%). De nuevo el hacha $\mathrm{n}^{\circ} 1$ se individualiza por superar el $2 \%$ As (tabla 2). 
Figura 3. Zona de posible localización del depósito de Yunclillos (círculo) y del yacimiento de Tributillos (cuadrado), el más cercano del Calcolítico/Edad del Bronce. Las líneas discontinuas en blanco marcan los límites entre los términos municipales de Bargas y Yunclillos. Cartografía base: Ortofoto PNOA (C IGN CNIG;

Cartografía Catastral

Rústica (C) Dirección General del Catastro.

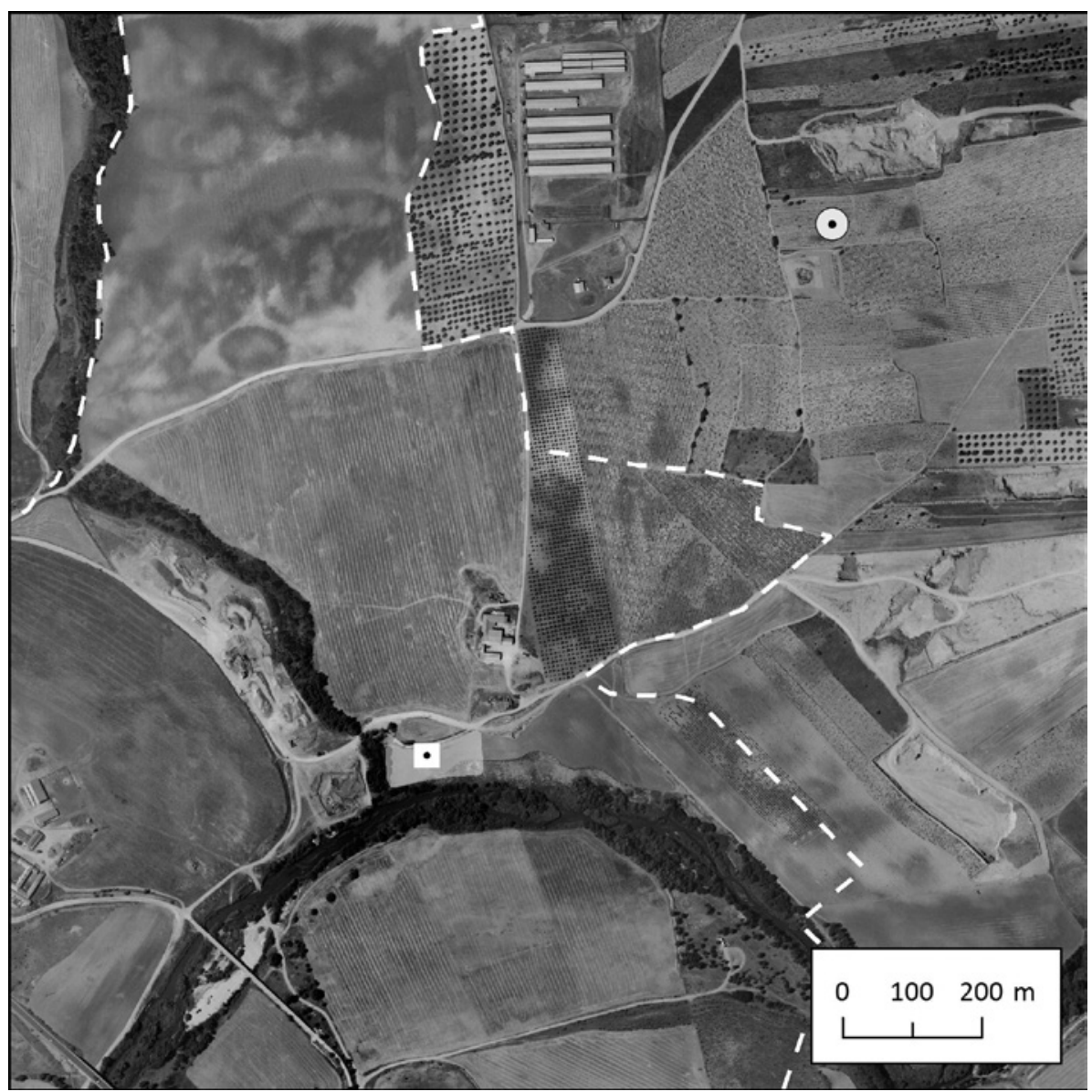

Figura 4. Reconstrucción de la posible colocación de las hachas del depósito de Yunclillos.
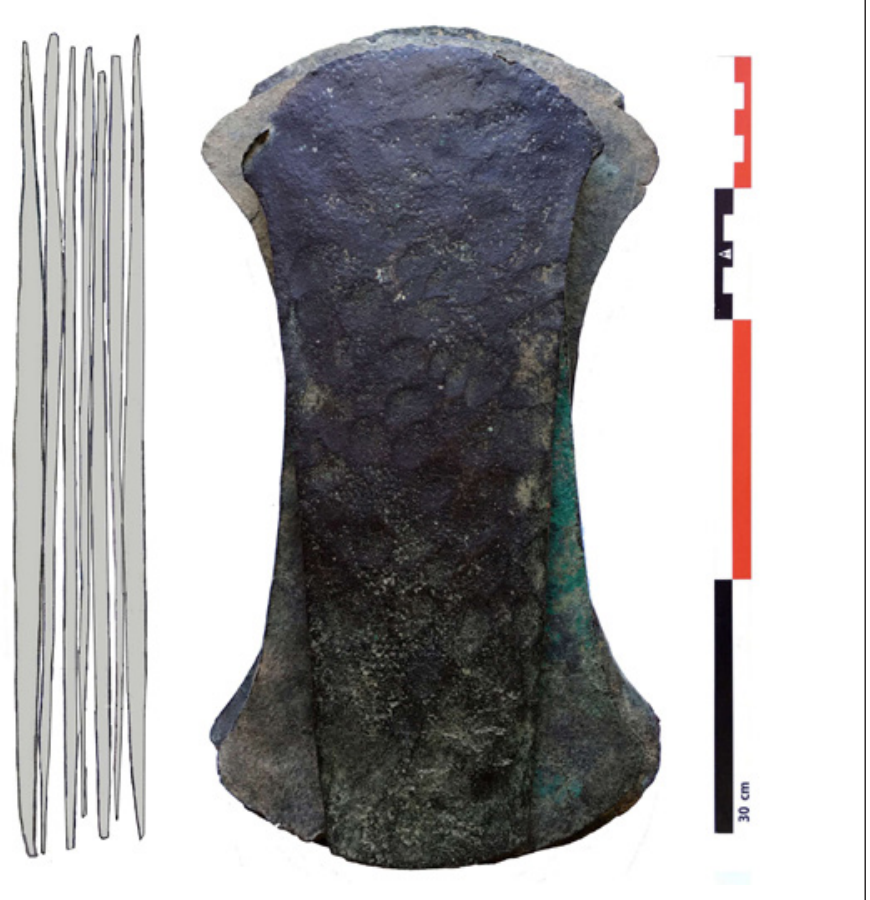


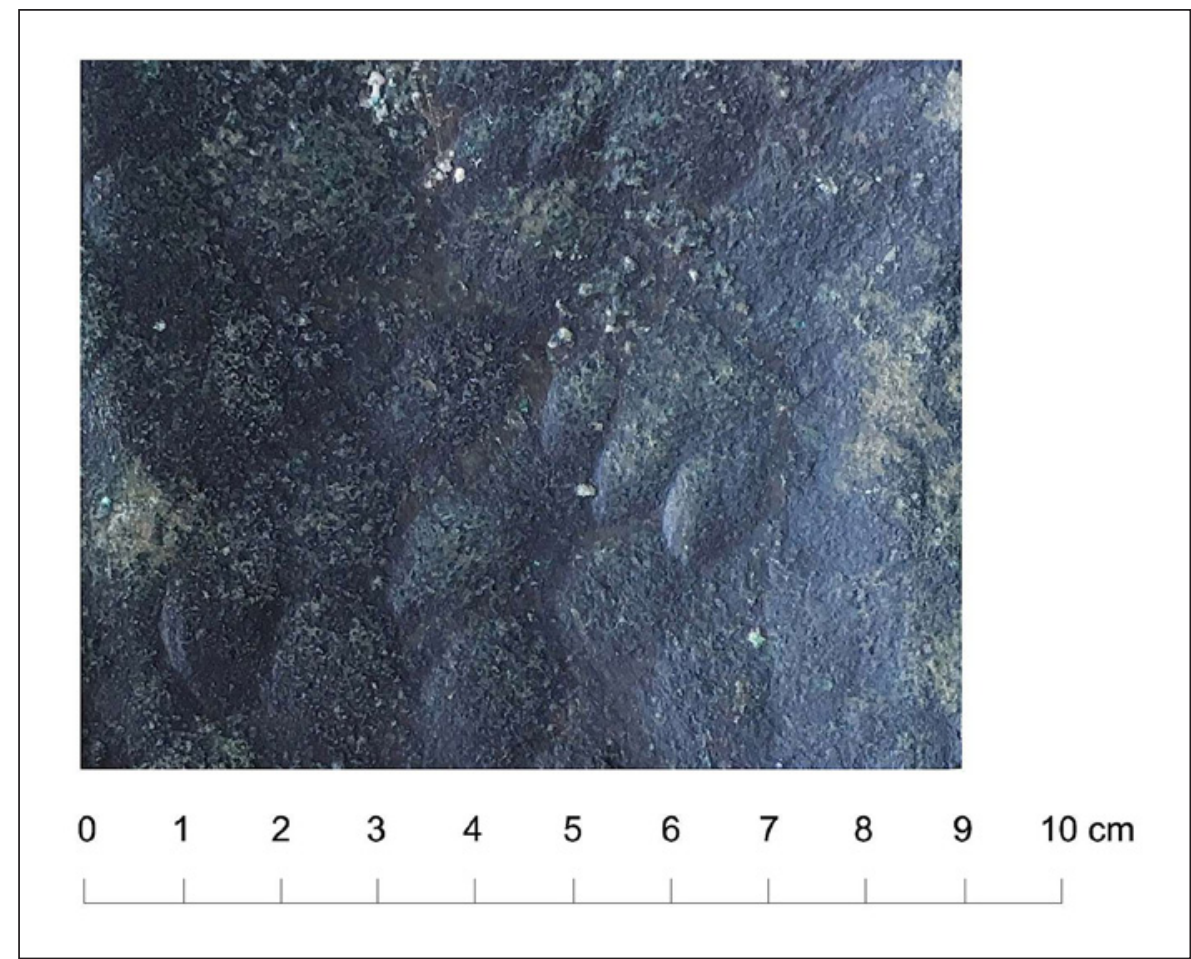

Figura 5. Detalle de las huellas que presenta en la superficie el hacha $\mathrm{n}^{\mathrm{o}} 1$ del depósito de Yunclillos.

\section{CATÁLOGO DE HACHAS PLANAS ANCHAS}

La presentación de la información sobre los ejemplares que, a nuestro juicio, responden a este grupo de hachas similar al de las piezas de Yunclillos es previa a cualquier discusión. Manejamos la información suministrada por las publicaciones de referencia y solo en aquellas inéditas $\mathrm{o}$ a las que hemos podido acceder en los museos donde se encuentran depositadas se incorporan datos como el peso. Las dimensiones y pesos se agrupan en la tabla 1 , junto a los datos del depósito de Yunclillos y las hachas planas de Asiego y Torreorgaz, como referencia para poder entender las diferencias formales con respecto a las hachas planas anchas y por su discusión en el texto a la hora de comentar los depósitos no funerarios de hachas planas.

\subsection{Valchica (Ejea de los Caballeros, Zaragoza) (fig. 1, $\mathrm{n}^{\circ}$ 12)}

Bardavíu (1922) notificó el hallazgo de una veintena sin mayor precisión- de hachas, en un campo de cultivo. Monteagudo (1977: $\mathrm{n}^{\mathrm{o}} 362-369$ y 371) menciona nueve depositadas en el Museo de Zaragoza. Las piezas se encuentran en buen estado de conservación y únicamente se puede destacar que la ${ }^{\circ} 367$ tiene la zona del filo ligeramente doblada y la $\mathrm{n}^{\circ} 363$ muestra marcas longitudinales en uno de los laterales (fig. 6). Las seis que hemos podido analizar son de cobre con arsénico (entre el $0,8 \%$ y $1,7 \%$ ). No hay referencia a ningún poblado prehistórico próximo.

\subsection{Cañada de las Cañas (Pozuelo de Calatrava, Ciudad Real) (fig. 1, $\mathrm{n}^{\circ}$ 6)}

Blanco de la Rubia (1983) documenta la aparición de trece hachas planas. Entre ellas estarían las dos publicadas por Monteagudo (1977: $\mathrm{n}^{\circ} 372-373$ ) como procedentes del Campo de Calatrava (fig. 6). Blanco de la Rubia (1983) dibuja y describe las tres hachas en propiedad de los descubridores y las denomina como A, $\mathrm{B}$ y C. Menciona que las diez restantes se entregaron a Martínez Santa-Olalla en el Instituto Arqueológico Municipal de Madrid. Las dos únicas registradas por Monteagudo están actualmente en el Museo Arqueológico Nacional (1973/58/clt/1 y 1973/58/clt/2). Proponemos que el hacha ingresada en el Museo de San Isidro con la Colección Sáez Martín (Quero Castro 2006) pertenezca al mismo conjunto (fig. 7), dadas las relaciones del coleccionista con Martínez Santa-Olalla y la pérdida de ocho hachas de este conjunto. Si fuera 
Tabla 1. Dimensiones y pesos de las hachas planas comentadas en el texto (longitud y anchura expresados en $\mathrm{cm}$; MAN=Museo Arqueológico Nacional, Madrid; MAS= Museo Arqueológico de Sevilla).

\begin{tabular}{|c|c|c|c|c|c|c|}
\hline Hachas & Long. max. & Anch. max. & Anch. talón & Grosor & Peso (g) & Referencias \\
\hline Cañada de las Cañas A & 26 & 13,8 & 7,2 & 0,7 & & Blanco de la Rubia 1983 \\
\hline Cañada de las Cañas B & 25,2 & 13,4 & 8,2 & 0,8 & & Blanco de la Rubia 1983 \\
\hline Cañada de las Cañas C & 25,9 & 12,5 & 7,2 & 0,8 & & Blanco de la Rubia 1983 \\
\hline Cañada de las Cañas 2 MAN & 27,6 & 14,3 & 7,5 & 0,9 & 1105 & Ficha inventario del MAN \\
\hline Cañada de las Cañas $1 \mathrm{MAN}$ & 26,7 & 14,5 & 7 & 0,75 & 1000,1 & Ficha inventario del MAN \\
\hline Hacha Museo S. Isidro & 27,6 & 13,3 & 7,8 & 0,75 & 1170 & Quero Castro 2006 \\
\hline Estepa CE1984/496 & 25,3 & 13 & 8,2 & 0,6 & 1065 & Ficha inventario del MAS \\
\hline Estepa CE1984/497 & 26 & 12,5 & 7 & 0,6 & 980 & Ficha inventario del MAS \\
\hline Estepa CE1984/494 & 24,8 & 12 & 7 & 0,7 & 940,6 & Ficha inventario del MAS \\
\hline Estepa CE1984/493 & 25,8 & 14,2 & 7,7 & 0,7 & 1050 & Ficha inventario del MAS \\
\hline Estepa CE1984/498 & 27 & 8,5 & 4,7 & 1,6 & 1685 & Ficha inventario del MAS \\
\hline Estepa CE1984/495 & 26,5 & 14 & 8 & 0,6 & 955,9 & Ficha inventario del MAS \\
\hline Cerrocuquillo 1 & 22,5 & 9,0 & & 0,4 & 1058 & Baquedano et al. 2010 \\
\hline Cerrocuquillo 2 & 22,1 & 9,0 & & 0,4 & 1012 & Baquedano et al. 2010 \\
\hline Valchica 362 & 24,4 & 9,4 & 7,5 & & & Monteagudo 1977 \\
\hline Valchica 363 & 24,4 & 9,1 & 9 & & & Monteagudo 1977 \\
\hline Valchica 364 & 24,4 & 9,3 & 10 & 0,5 & & Monteagudo 1977 \\
\hline Valchica 365 & 23,3 & 8,9 & 8 & & & Monteagudo 1977 \\
\hline Valchica 366 & 23,8 & 11,1 & 8 & & & Monteagudo 1977 \\
\hline Valchica 367 & 24,2 & 10,4 & 7 & & & Monteagudo 1977 \\
\hline Valchica 368 & 24,2 & 10,5 & 7,5 & & & Monteagudo 1977 \\
\hline Valchica 369 & 22,3 & 9,2 & 8 & & & Monteagudo 1977 \\
\hline Valchica 371 & 22,9 & 11,7 & 9 & & 1120 & Monteagudo 1977 \\
\hline Yunclillos 1 & 28,7 & 12,7 & 7 & 1 & 1614 & Este trabajo \\
\hline Yunclillos 2 & 27,1 & 16,1 & 10,2 & 0,5 & 1254 & Este trabajo \\
\hline Yunclillos 3 & 31,1 & 16 & 8,8 & 0,7 & 1355 & Este trabajo \\
\hline Yunclillos 4 & 30,6 & 17,5 & 9,4 & 0,4 & 1331 & Este trabajo \\
\hline Yunclillos 5 & 30 & 15,4 & 8,2 & 0,7 & 1228 & Este trabajo \\
\hline Yunclillos 6 & 28,5 & 16,7 & 11 & 0,7 & 992 & Este trabajo \\
\hline Yunclillos 7 & 28,2 & 15,2 & 10 & 0,8 & 1306 & Este trabajo \\
\hline Sanguino & 24,4 & 11,8 & 6,3 & 0,8 & & Este trabajo \\
\hline Mieres & 23 & 9,7 & 9 & & & Monteagudo 1977 \\
\hline
\end{tabular}




\begin{tabular}{|l|c|c|c|c|c|l|}
\hline \multicolumn{1}{|c|}{ Hachas } & Long. max. & Anch. max. & Anch. talón & Grosor & Peso $(\mathrm{g})$ & \multicolumn{1}{|c|}{ Referencias } \\
\hline Seurre & 25,0 & & 7,0 & 0,60 & & Monteagudo 1977 \\
\hline Mondouzil 1 & 24,1 & 12,0 & 6,7 & 0,80 & & Klassen et al. (2007) \\
\hline Mondouzil 2 & 23,6 & 10,3 & 6,3 & 0,80 & & Klassen et al. (2007) \\
\hline Santa Catalina & 17,2 & 9,8 & 4,5 & 0,60 & & Klassen et al. (2007) \\
\hline Asiego 183 & 16,7 & 6,0 & & 1,55 & & Monteagudo 1977 \\
\hline Asiego184 & 18,7 & 6,8 & & 1,30 & & Monteagudo 1977 \\
\hline Asiego185 & 18,9 & 6,8 & & 1,65 & & Monteagudo 1977 \\
\hline Asiego186 & 21,0 & 7,4 & & 1,75 & & Monteagudo 1977 \\
\hline Asiego187 & 19,1 & 7,0 & & 1,50 & & Monteagudo 1977 \\
\hline Torreorgaz 1973/62/34 & 21,7 & 6,9 & & 1,40 & 1013,8 & Rovira et al. 1997 \\
\hline Torreorgaz 1973/62/35 & 22,6 & 6,8 & & 1,50 & 1138,3 & Rovira et al. 1997 \\
\hline Torreorgaz 1973/62/36 & 22,3 & 6,5 & & 1,35 & 938,7 & Rovira et al. 1997 \\
\hline Torreorgaz 1973/62/37 & 21,3 & 6,5 & & 1,65 & 1046,9 & Rovira et al. 1997 \\
\hline Torreorgaz 52 & 11,5 & 3,8 & & 0,80 & & Monteagudo 1977 \\
\hline Torreorgaz 176 & 20,4 & 6,2 & & 1,50 & & Monteagudo 1977 \\
\hline Torreorgaz 177 & 21,1 & 5,7 & & 1,50 & & Monteagudo 1977 \\
\hline Cerro del Judío & 19,5 & 7,2 & & & & Monteagudo 1977 \\
\hline
\end{tabular}

así dispondríamos de datos de seis de las trece hachas que formarían el depósito.

El hacha del Museo de San Isidro presenta el filo romo, la superficie con huellas de martillado y los bordes ligeramente levantados (fig. 7). Blanco de la Rubia (1983) relaciona este hallazgo por su proximidad geográfica con el yacimiento de Castillejo de Acebuchal, encuadrado en un Bronce Antiguo y Pleno por la presencia de material cerámico carenado. Según la descripción el depósito apareció en la falda de la sierra junto a la llanura, a $500 \mathrm{~m}$ al noroeste del yacimiento.

Las dos hachas del Museo Arqueológico Nacional (MAN) y la del Museo de San Isidro son de cobre con arsénico entre 1,8-2,7\% y pequeñas impurezas de plomo en las piezas del MAN (tabla 2).

\subsection{Estepa (Sevilla) (fig. 1, $\left.\mathrm{n}^{\mathrm{o}} 2\right)$}

Este conjunto se conoce gracias a la publicación de la composición de las seis hachas analizadas por el Proyecto de Arqueometalurgia (Rovira et al. 1997) y a las referencias de Fernández Gómez (2003, 2004) en catálogos de exposición. Sabemos que ingresaron en el Museo de Sevilla en 1984, pero no hay datos del contexto del hallazgo y la cronología que propone Fernández Gómez creemos que es errónea, como detallaremos en el apartado correspondiente. El hacha ${ }^{\circ} 498$ se distingue formalmente de las cinco restantes por su menor anchura de cuerpo y talón $(8,4 \mathrm{~cm})$ y su mayor peso (1700 g frente a $1000 \mathrm{~g}$ del resto) y grosor. Estas proporciones la acercan más al cincel que al hacha (fig. 8). Las improntas que algunas hachas conservan en la pátina sugieren que se depositaron y hallaron apiladas. Todas se componen de cobre sin alear con menos de un $1 \%$ As, aunque los valores están infravalorados en la serie de análisis realizados con el Kevex (Rovira y Montero Ruiz 2018). Con valores corregidos estaríamos en proporciones entre el 1-2\% As.

\subsection{Cerrocuquillo (Villaluenga de la Sagra, Toledo) (fig. 1, $\mathrm{n}^{\circ} 8$ )}

Las excavaciones en este yacimiento han definido tres poblados superpuestos (Calcolítico/Bronce Antiguo, I 


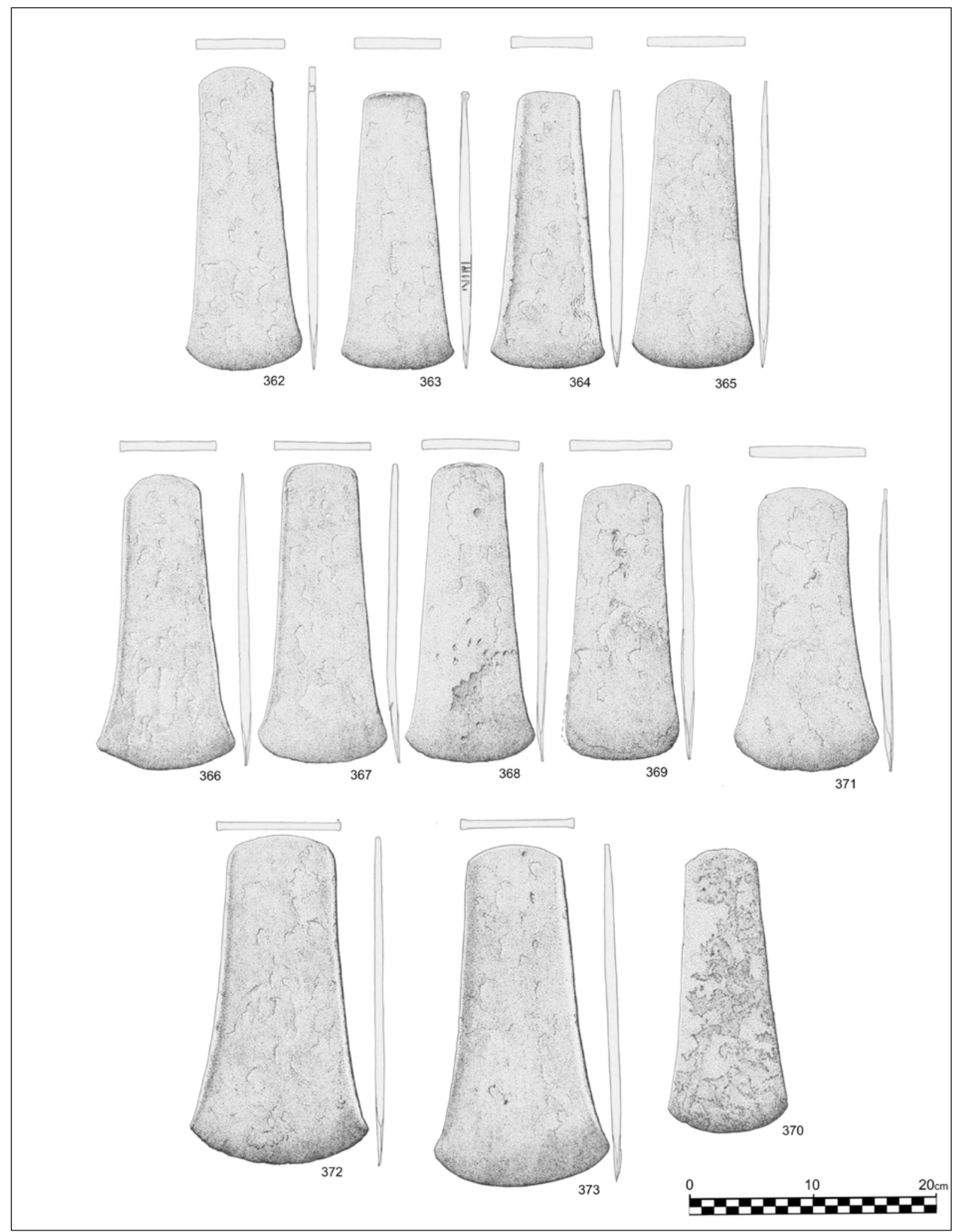

Figura 6. Hachas del grupo 5 de Monteagudo (1977): números 362 a 3769 y 371 de Valchica (Ejea de los Caballeros), n 370 de Mieres y números 371-372 de Campo de Calatrava o Cañada de las Cañas (sin escala en el original). 


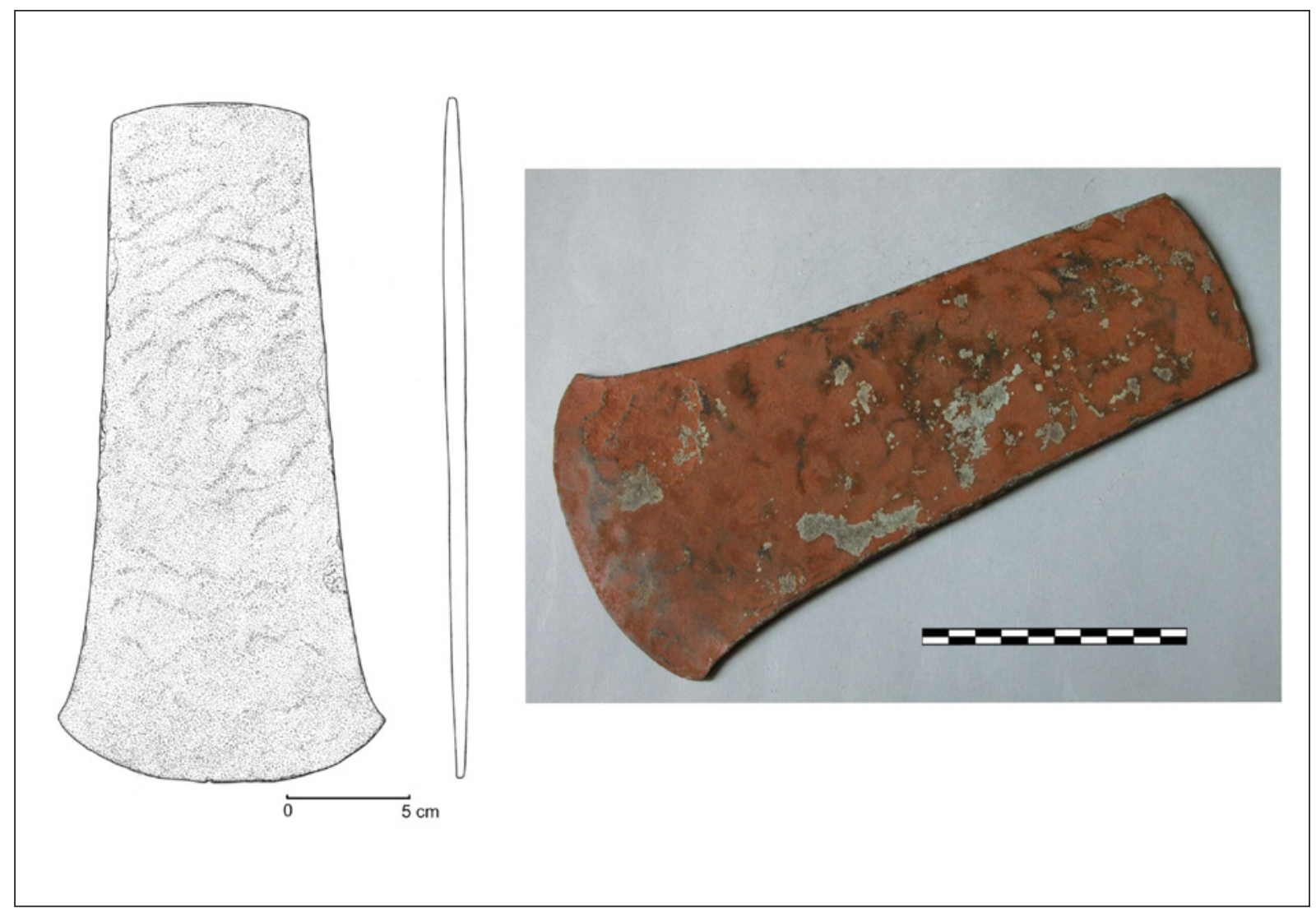

Figura 7. Hacha del Museo de San Isidro (dibujo y fotografía Oscar García Vuelta).

Edad del Hierro y etapa carpetana). Fuera de contexto se recuperaron dos hachas planas de cobre que encajan tipológicamente con las que tratamos en este artículo. Las vinculamos con el poblado de "fondos de cabaña" o "campo de silos" típicos de la Prehistoria reciente (III y II milenios a.C.) (Baquedano et al. 2010). Los análisis indican que ambas hachas son de cobre con menos de un $1 \%$ As.

\subsection{Hacha de Sanguino (Toledo)}

El Museo de Santa Cruz de Toledo la adquirió al anticuario Mauricio Sanguino. El hacha carece de más localización que su probable pertenencia a la provincia de Toledo. Sus dimensiones son menores que las del depósito de Yunclillos y Cañada de las Cañas (fig. 9, tab. 1) por lo que no parece tener relación con ninguno de ellos. Su principal rasgo es que el extremo correspondiente al filo es romo, es decir, está sin acabar. La composición del metal es cobre arsenicado (0,97-1,38\% As).
3.6. Mieres (Asturias) (fig. 1, $\mathrm{n}^{\mathrm{o}} 12$ )

El hacha ingresó en el Museo Arqueológico Nacional con $\mathrm{n}^{\circ}$ de inventario 10127 (Monteagudo 1977: $\mathrm{n}^{\mathrm{o}}$ 370) (fig. 2). No se conocen detalles sobre su aparición. Según el análisis AA0918 es un cobre que además de arsénico $(0,5 \%)$, y a diferencia del de otras piezas, contiene un $2 \% \mathrm{Sb}$ y $0,36 \% \mathrm{Ag}$. Estos valores altos $(1,5 \%$ $\mathrm{Sb} ; 0,45 \% \mathrm{Ag})$ también fueron detectados en el análisis del SAM (Junghans et al. 1968: n 2209). Blas (1999: $53)$ encuadra cronológicamente este hacha en el periodo del Bronce Antiguo (finales del III inicios del II milenio cal AC).

\subsection{Seurre (Côte-d'Or, Francia) (fig. 1, no 14)}

El hacha se recuperó entre material procedente del drenaje del río Saona (fig. 9). Está depositada en el $\mathrm{Mu}-$ seo Denon de Chalon-sur-Saône. Según Klassen et al. (2007) es una pieza española importada, vinculada con el Campaniforme. 


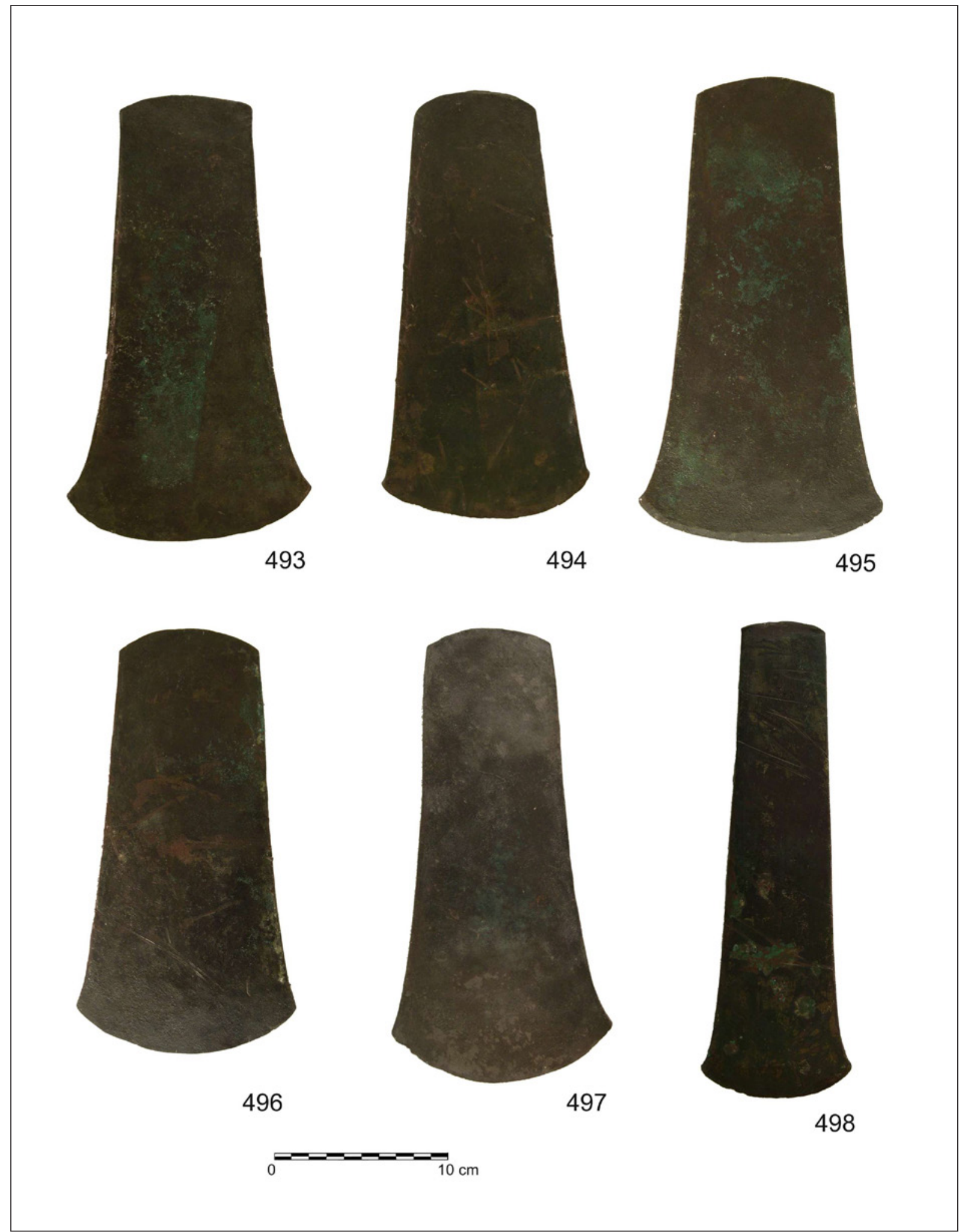

Figura 8. Hachas del depósito de Estepa (Sevilla). El número corresponde a la parte final de su número de inventario en el Museo Arqueológico de Sevilla (CE1984/ ) y coincide con la descripción de la tabla 1 (fotografías de Mark Hunt). 


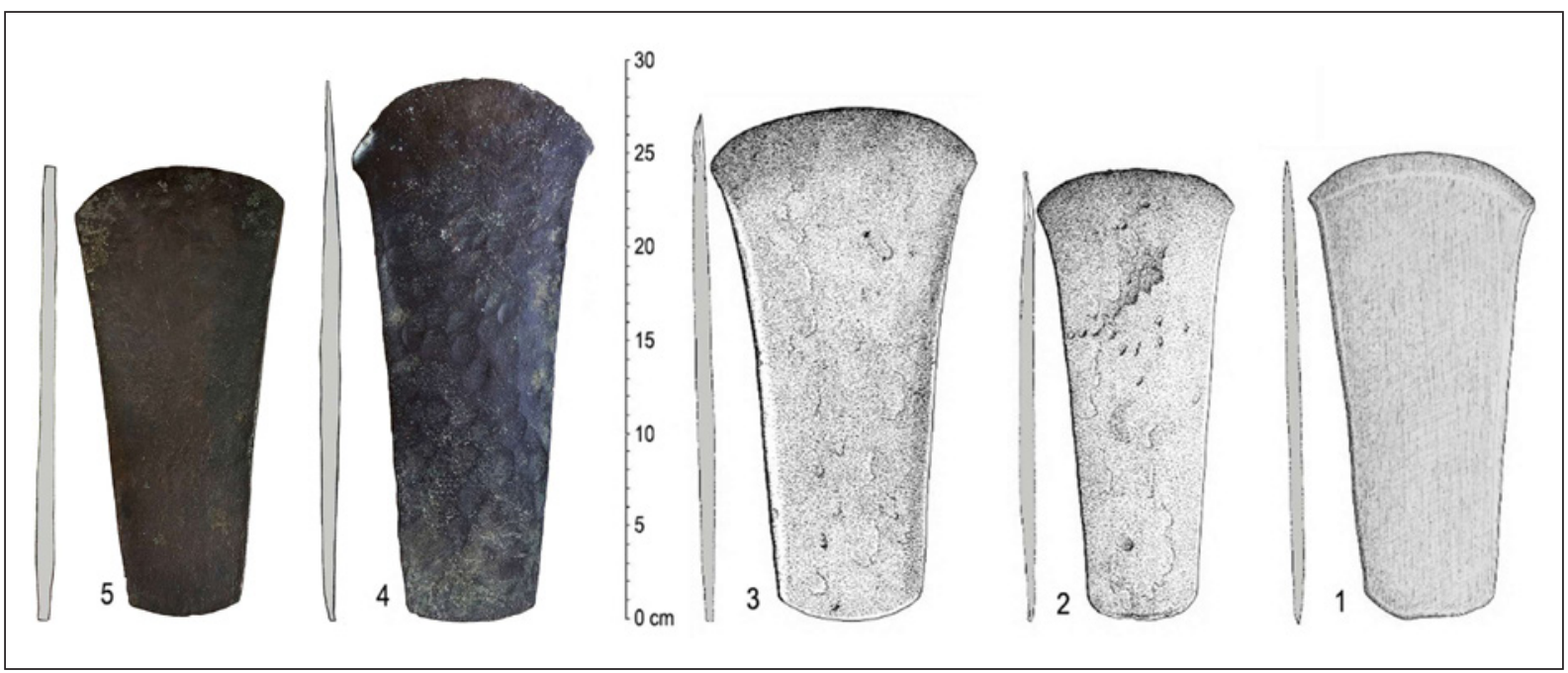

Figura. 9. Comparación del hacha de Seurre (1) con las hachas planas anchas de la península ibérica: Ejea de los Caballeros (2) y Cañada de las Cañas (3), según Klassen et al. (2007: fig, 12, modificada); Número 1 de Yunclillos (4) y Sanguino (5).

\subsection{Mondouzil (Châteauneuf-sur- Charente, Francia) (fig. 1, n ${ }^{\circ} 13$ )}

Las dos hachas proceden de un hallazgo antiguo. Sus rasgos formales, tamaño, espesor coinciden con los de las hachas hasta ahora enumeradas pero los contornos son mas redondeados. Una lleva ligeros rebordes en una cara. Klassen, Pétrequin y Grut (2007) las consideran similares a la de Seurre y a las de Valchica (Ejea de los Caballeros). Según los análisis de composición recopilados realizados por Jean Bourhis (Roussot-Larroque 1997; Gómez 1998), ambas son de cobre arsenicado ( $2 \%$ y $1,5 \%$ As respectivamente).

\subsection{Santa Catalina (Verdolay, Murcia) (fig. 1, $\mathrm{n}^{\mathrm{o}}$ 3)}

El hacha publicada por Muñoz Amilibia (1984-85) procedente de una sepultura argárica de Santa Catalina no llega a los $20 \mathrm{~cm}$ que habíamos fijado para la comparación, pero la consideramos una referencia útil. El hacha se aleja tipológicamente de las conocidas en el Calcolítico y Edad del Bronce del Sureste peninsular y, por sus dimensiones, queda fuera de los índices establecidos por Lull (1983) para estas piezas. Mide 17,2 cm de longitud máxima, $9,8 \mathrm{~cm}$ de filo y $4,5 \mathrm{~cm}$ de anchura en el talón, cuyo espesor es solo de 0,4 cm. Esta delgadez, que calculamos en un máximo de 0,5 o $0,6 \mathrm{~cm}$, la alinea con el tipo de hacha ancha y delgada bajo estudio. Además los ligeros rebordes (menos de $1 \mathrm{~mm}$ ) presentes en una cara también se han identificado en alguna de las hachas de Cañada de las Cañas y Mondouzil.

\section{TECNOLOGÍA DE MANUFACTURA}

\subsection{Metodología de estudio}

Para el desarrollo de este apartado utilizaremos la información obtenida del estudio visual de las piezas, complementada por el estudio metalográfico de dos de las hachas de Yunclillos y el análisis elemental de las piezas españolas realizadas dentro del Proyecto Arqueometalurgia de la Península Ibérica.

Las metalografías se han realizado en los laboratorios del Instituto de Historia del CSIC. Las muestras fueron embutidas en bloques de resina bi-componente autopolimerizante (metacrilato de metilo) de fraguado rápido, utilizando moldes de caucho. Los bloques fueron primero desbastados en húmedo utilizando cinco papeles de lija de carburo de silicio desde el tamaño de grano más grueso (P100) hasta el más fino (P1200), usando una pulidora automática PRESI Modelo Mecapol con brazo P.E.R.U. y cabezal de seis probetas. En el desbastado se utilizó una velocidad de rotación de disco de $250 \mathrm{rpm}$ y suministro de agua. La orientación de las probetas se fue rotando $90^{\circ}$ con cada papel de lija. Posteriormente fueron pulidas empleando paños de fieltro con una solución de alúmina en suspensión $(99,98 \% \mathrm{Al})$ hasta un tamaño de grano de $0,04 \mu$, 
Figura 10. Metalografía del hacha $\mathrm{n}^{\circ} 3$ del depósito de Yunclillos (Proyecto Arqueometalurgia de la Península Ibérica).

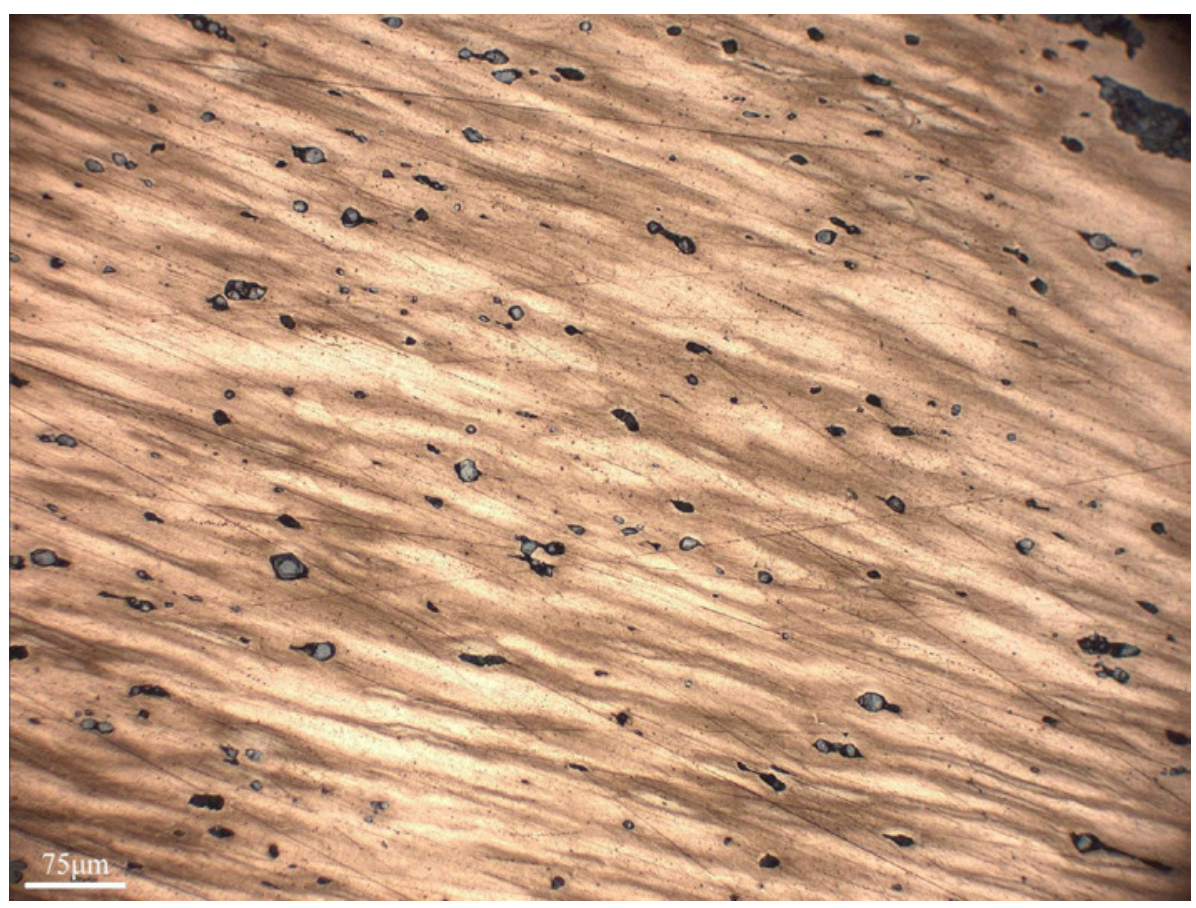

con una velocidad de 200rpm y un tiempo de pulido variable. Una vez pulidas, las piezas se atacaron con solución acuosa de cloruro férrico [60 $\mathrm{ml}$ de agua destilada, $15 \mathrm{ml}$ de ácido clorhídrico $(\mathrm{HCl})$ y $5 \mathrm{~g}$ de cloruro férrico $(\mathrm{FeCl} 3)]$ durante cinco segundos y se observaron en el microscopio óptico Leica DMLM con cámara digital acoplada.

El análisis elemental (tabla 2) se ha realizado mediante la técnica de espectrometría de fluorescencia de rayos $X$, eliminando una pequeña superficie de la patina y empleando equipamientos diferentes según el momento en el que fueron analizadas. Los análisis de las hachas de Estepa y la de Mieres utilizaron el espectrómetro KEVEX mod 7000 con fuente de ${ }^{241} \mathrm{Am}$, las hachas de Cerrocuquillo y del Museo de San Isidro emplearon el espectrómetro METOREX también con fuente de ${ }^{241} \mathrm{Am}$ y el resto de hachas un espectrómetro portátil INNOV-X seria Alpha con tubo de rayos $\mathrm{X}$. Las características de estos equipamientos, así como los procedimientos seguidos para su calibración y la comparación de resultados obtenidos se encuentran recogidos en el trabajo de Rovira y Montero Ruiz (2018).

\subsection{Técnica de fabricación}

La delgadez de las secciones de las hachas y la ausencia de rebabas o huellas de las costuras laterales hacen pensar que se fundieron en un molde monovalvo, quizás en algún caso cubierto por una valva plana. Los ligeros rebordes por una cara de los ejemplares de Cañada de las Cañas y Mondouzil pueden explicarse por la tensión superficial del metal en la pared del molde durante su enfriamiento. No hace falta pensar que estuvieran cubiertos por una segunda valva. Solo el ejemplar $n^{\circ} 2$ de Yunclillos muestra defectos superficiales en la colada, como oquedades en el centro de una de sus caras.

Las huellas de martillado repartidas por toda la superficie en las hachas del Museo de San Isidro y en la $\mathrm{n}^{\mathrm{o}} 1$ de Yunclillos son excepción en la metalurgia de la península ibérica (fig. 8). Es cierto que para terminar de conformar determinados objetos es necesario un trabajo de forja en frío. Sin embargo lo habitual en las hachas producidas a molde es que esa forja se concentre en los filos para adelgazarlos y endurecerlos. La forja intensa del cuerpo es innecesaria y así lo muestran las metalografías de los filos de las hachas desde el Calcolítico. En cambio, la metalografía realizada en el talón de un hacha de Almizaraque confirma una estructura de bruto de colada sin forja (Gener et al. 2009).

Hemos podido metalografiar la zona de los filos de las hachas $n^{\circ} 3$ y 4 de Yunclillos. La muestra de la $n^{\circ} 3$ (PA21301) presenta la micro-estructura característica del trabajo de forja en frío (fig. 10): una deformación, aplanamiento y reducción del grosor de la estructura 

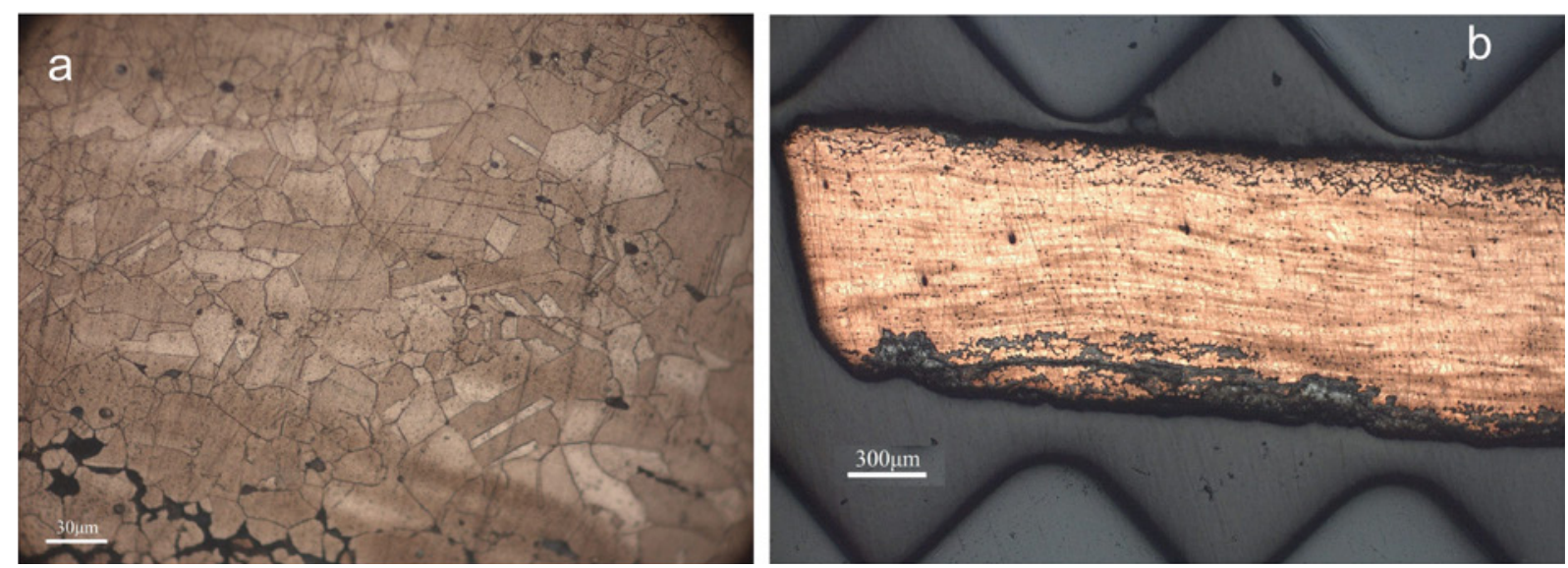

Figura 11. Metalografías en la zona del filo del hacha $n^{\circ} 4$ del depósito de Yunclillos: a) detalle de los pequeños granos equiaxiales con maclas en su interior; b) microestructura general de forja (Proyecto Arqueometalurgia de la Península Ibérica).

dendrítica inicial. Las bandas claras corresponderían al remanente de los granos dendríticos y las bandas oscuras, a los espacios interdendríticos previos. Se ven también abundantes inclusiones de sulfuro de cobre y, esporádicamente, de cuprita. Ambas aparecen con tono azulado en la figura 10, pero cuando se observan las muestras en campo oscuro tornan a tonalidades negras y rojas respectivamente. Estas inclusiones no aparecen deformadas y aplanadas como consecuencia de la forja, como les ocurre a algunos de los poros visibles. Ello evidencia asimismo que la forja no resultó excesivamente intensa.

Esta deformación micro-estructural fruto del martilleado en frío confiere una mayor dureza al metal, pero le resta ductilidad y maleabilidad. Llega un punto en que el metal es demasiado frágil para continuar la forja sin que aparezcan fracturas. Si se quiere seguir, el metal tiene que ser recocido de nuevo para recobrar algo de la maleabilidad y la ductilidad perdidas durante la forja. Durante el recocido (a temperaturas siempre inferiores a las del punto de fusión), el metal vuelve a cristalizar en granos equi-axiales de formas aproximadamente hexagonales. Una vez terminada esta fase de recocido puede repetirse una segunda fase de forja. En el hacha $\mathrm{n}^{\circ} 3$ no se observan granos de recocido, por lo que la forja debió ser lo bastante intensa como para deformar por completo la estructura dendrítica, pero no tanto como para requerir un recalentamiento del metal. Tampoco se observan fracturas que evidencien de forma clara que se alcanzó el límite de deformación del metal.

El hacha ${ }^{\circ} 4$ (PA21302) también presenta una micro-estructura de forja, pero en ella sí se observan, a mayores aumentos, pequeños granos equi-axiales con maclas en su interior, evidencia de que la pieza sí se vio sometida a una última fase de recocido (fig. 11). No obstante, este recocido no habría sido muy intenso, ya que la microestructura de forja sigue siendo evidente a bajos aumentos. Se advierte la disposición de los poros en bandas horizontales, aunque sin una morfología excesivamente aplanada (fig. 11b). De esta pieza se tomaron dos muestras, una en la zona del filo y otra más al interior, sin que se observen diferencias microestructurales entre ellas.

Ello pone de manifiesto que este tratamiento afectó, al menos, a toda el área curva del filo y no solo a su parte más extrema. En este contexto tecnológico de preparación de filos llama la atención que el del hacha de Sanguino sea romo (fig. 5). Este hacha podríamos considerarla inacabada, ya que están biselados el filo y el talón a falta solo del procesado final. El espesor del bisel es de $0,5 \mathrm{~cm}$. La otra hacha con filo romo es la del Museo de San Isidro, atribuida por nosotros al depósito de Cañada de las Cañas. Su superficie presenta, además, las huellas que atribuimos a un martillado, sin que realmente se haya preparado el filo de la pieza.

En cualquier caso, aunque las hachas se sometan a un trabajo de forja, se borran las huellas de martillado. En consecuencia, su presencia visible en estos dos ejemplares debe responder a intereses especiales. La secuencia repetitiva y ordenada de unas improntas ovales superficiales que los cubren por completo es una singularidad no documentada por el momento en otras hachas peninsulares. Este tratamiento superficial, cuya justificación no está en la manufactura de las piezas, quizás podría buscar un efecto estético. La decoración 
Tabla 2. Composición ( $\%$ en peso) de las hachas planas anchas citadas en el texto $(\mathrm{ND}=$ por debajo del límite de detección; $\operatorname{tr}=$ trazas).

\begin{tabular}{|c|c|c|c|c|c|c|c|c|c|c|c|}
\hline NUM_ANALIS & LOCALIDAD & $\begin{array}{l}\text { NUM_- }_{\text {INVENT }}\end{array}$ & $\mathrm{Fe}$ & $\mathrm{Ni}$ & $\mathrm{Cu}$ & As & $\mathrm{Ag}$ & $\mathrm{Sn}$ & $\mathrm{Sb}$ & $\mathrm{Pb}$ & $\mathrm{Bi}$ \\
\hline AA0918 & Mieres & 10127 & 0,06 & 0,11 & 95,8 & 0,59 & 0,36 & ND & 2,03 & 0,2 & ND \\
\hline Bourhis & Mondouzil & $\mathrm{n}^{\mathrm{o}} 2$ & 0,015 & 0,008 & 98 & 1,5 & 0,04 & 0,004 & 0,2 & 0,005 & 0,08 \\
\hline Bourhis & Mondouzil & $\mathrm{n}^{\mathrm{o}} 1$ & & 0,001 & 98,7 & 2 & 0,04 & 0,25 & 0,05 & - & 0,008 \\
\hline PA10553 & Museo San Isidro & $2001 / 1 / 1$ & 0,2 & ND & 97,7 & 2,05 & 0,016 & ND & 0,01 & ND & ND \\
\hline PA12381 & Cerrocuquillo & $\mathrm{n}^{\mathrm{o}} 1$ & ND & ND & 99 & 0,51 & 0,035 & 0,04 & 0,15 & 0,29 & ND \\
\hline PA12382 & Cerrocuquillo & $\mathrm{n}^{\mathrm{o}} 2$ & 0,11 & ND & 98,6 & 0,89 & 0,021 & 0,05 & 0,15 & 0,21 & ND \\
\hline PA20916A & Yunclillos & TR-1 & ND & ND & 97 & 2,73 & $<0,15$ & 0,05 & $<0,15$ & ND & ND \\
\hline PA20916B & Yunclillos & TR-1 & ND & ND & 97,8 & 2,14 & $<0,15$ & ND & $<0,15$ & ND & ND \\
\hline PA20917A & Yunclillos & TR -2 & ND & ND & 98,4 & 1,36 & $<0,15$ & ND & $<0,15$ & ND & ND \\
\hline PA20917B & Yunclillos & TR -2 & ND & ND & 98,0 & 1,99 & $<0,15$ & ND & $<0,15$ & ND & ND \\
\hline PA21301A & Yunclillos & TR-3 & 0,57 & ND & 97,7 & 1,74 & $<0,15$ & ND & $<0,15$ & ND & ND \\
\hline PA21301B & Yunclillos & TR -3 & 0,37 & ND & 98,1 & 1,55 & $<0,15$ & ND & $<0,15$ & ND & ND \\
\hline PA21302 & Yunclillos & $\mathrm{TR}-4$ & ND & ND & 99,8 & 0,18 & $<0,15$ & ND & $<0,15$ & ND & ND \\
\hline PA21303 & Yunclillos & TR-5 & 0,12 & ND & 98,7 & 1,14 & $<0,15$ & ND & $<0,15$ & ND & ND \\
\hline PA21304A & Yunclillos & TR-6 & 0,13 & ND & 99,1 & 0,74 & $<0,15$ & ND & $<0,15$ & ND & ND \\
\hline PA21304B & Yunclillos & TR-6 & 0,22 & ND & 99 & 0,77 & $<0,15$ & ND & $<0,15$ & ND & ND \\
\hline PA21305 & Yunclillos & TR-7 & 0,07 & ND & 98,9 & 1,04 & $<0,15$ & ND & $<0,15$ & ND & ND \\
\hline PA21524 & Valchica & 2643 & 0,27 & ND & 98,2 & 1,52 & $<0,15$ & ND & $<0,15$ & ND & ND \\
\hline PA2 21525 & Valchica & 2642 & 0,05 & ND & 98,5 & 1,46 & $<0,15$ & ND & $<0,15$ & ND & ND \\
\hline PA21526 & Valchica & 2639 & 0,06 & ND & 99,1 & 0,88 & $<0,15$ & ND & $<0,15$ & ND & ND \\
\hline PA21527 & Valchica & 2638 & 0,09 & ND & 98,9 & 0,97 & $<0,15$ & ND & $<0,15$ & ND & ND \\
\hline PA2 1528 & Valchica & 2644 & ND & ND & 98,3 & 1,66 & $<0,15$ & ND & $<0,15$ & ND & ND \\
\hline PA21529 & Valchica & 2636 & 0,04 & ND & 99 & 0,82 & $<0,15$ & ND & 0,14 & ND & ND \\
\hline PA25686A & $\begin{array}{l}\text { Hacha de } \\
\text { Sanguino }\end{array}$ & $1996 / 21 / 1$ & ND & ND & 99 & 0,97 & $<0,15$ & 0,05 & $<0,15$ & ND & ND \\
\hline PA25686B & $\begin{array}{l}\text { Hacha de } \\
\text { Sanguino }\end{array}$ & $1996 / 21 / 1$ & 0,03 & ND & 98,5 & 1,38 & $<0,15$ & 0,07 & $<0,15$ & 0,03 & ND \\
\hline PA25879 & $\begin{array}{l}\text { Cañada de las } \\
\text { Cañas }\end{array}$ & $1973 / 58 / \mathrm{clt} / 1$ & 0,09 & ND & 97,1 & 2,71 & $<0,15$ & ND & $<0,15$ & 0,06 & ND \\
\hline PA25880 & $\begin{array}{l}\text { Cañada de las } \\
\text { Cañas }\end{array}$ & $1973 / 58 / \mathrm{clt} / 2$ & ND & ND & 98,0 & 1,84 & $<0,15$ & ND & $<0,15$ & 0,04 & 0,1 \\
\hline PA5853 & Estepa & CE1984/498 & 0,11 & ND & 99,2 & 0,64 & 0,001 & ND & 0,003 & nd & - \\
\hline PA5855 & Estepa & CE1984/493 & 0,07 & 0,06 & 99,5 & 0,28 & 0,005 & $\operatorname{tr}$ & 0,004 & 0,03 & - \\
\hline
\end{tabular}




\begin{tabular}{|l|l|c|c|c|c|c|c|c|c|c|c|}
\hline NUM_ANALIS & LOCALIDAD & $\begin{array}{c}\text { NUM_ } \\
\text { INVENT }\end{array}$ & $\mathrm{Fe}$ & $\mathrm{Ni}$ & $\mathrm{Cu}$ & $\mathrm{As}$ & $\mathrm{Ag}$ & $\mathrm{Sn}$ & $\mathrm{Sb}$ & $\mathrm{Pb}$ & $\mathrm{Bi}$ \\
\hline PA5856 & Estepa & $\mathrm{CE} 1984 / 494$ & 0,08 & $\mathrm{ND}$ & 99 & 0,9 & 0,01 & $\mathrm{ND}$ & 0,003 & $\mathrm{ND}$ & - \\
\hline PA5857 & Estepa & $\mathrm{CE} 1984 / 495$ & 0,05 & $\mathrm{ND}$ & 99,2 & 0,67 & 0,002 & 0,01 & 0,006 & $\mathrm{ND}$ & - \\
\hline PA5858 & Estepa & $\mathrm{CE} 1984 / 496$ & 0,04 & $\mathrm{ND}$ & 99,4 & 0,54 & 0,003 & $\mathrm{ND}$ & 0,005 & $\mathrm{ND}$ & - \\
\hline PA5859A & Estepa & $\mathrm{CE} 1984 / 497$ & 0,06 & 0,11 & 98,9 & 0,86 & 0,001 & $\mathrm{ND}$ & 0,003 & $\mathrm{ND}$ & - \\
\hline PA5859B & Estepa & $\mathrm{CE} 1984 / 497$ & 0,11 & 0,06 & 98,7 & 1,09 & 0,002 & $\mathrm{ND}$ & 0,004 & $\mathrm{ND}$ & - \\
\hline
\end{tabular}

Los análisis del Proyecto Arqueometalurgia de la Península Ibérica (análisis AA y PA) se han obtenido por espectrometría de fluorescencia de rayos $\mathrm{X}$ con distintos equipos según se indica en el texto. Los altos límites de detección de la plata (Ag) y antimonio $(\mathrm{Sb})$ se indica en los análisis realizados con el espectrómetro INNOV-X como valor $<0,15 \%$. Los análisis de Bourhis fueron realizados en el Laboratoire d'Anthropologie de l'Université de Rennes y publicados por Roussot Larroque (1997). Los análisis de Mieres y Estepa se publicaron en Rovira et al. (1997) y los de Cerrocuquillo en Baquedano et al. (2010). El resto son análisis inéditos.

es un rasgo ausente en las hachas planas peninsulares, pero detectado en otros ámbitos geográficos de Europa occidental en la Edad del Bronce, especialmente en Inglaterra e Irlanda (Harding 2003). Las improntas de los ejemplares manchegos podrían sugerirnos las decoraciones de líneas en hachas de depósitos del Bronce Antiguo (Needham et al. 1985).

\subsection{Composición elemental de las hachas}

Disponemos de datos sobre la composición de la mayoría de los ejemplares enumerados (tab. 2). Al tratarse de piezas de gran tamaño con un gran consumo de metal, en las hachas de Yunclillos hemos intentado analizar dos puntos en partes opuestas de las piezas, filo (A) y talón (B). Los resultados muestran una pequeña variabilidad normal en piezas prehistóricas, en estos análisis la mayor diferencia detectada en el arsénico es de $0,6 \%$ y confirman que podemos tomar como validos los análisis únicos de otras piezas.

Todas las hachas son de cobre con una cantidad de arsénico que oscila entre el $0,18 \%$ del hacha $n^{\circ} 4$ de Yunclillos y el 2,7\% de las hachas de Yunclillos $\left(\mathrm{n}^{\circ} 1\right)$ y Cañada de las Cañas (1973/58/clt/1) del Museo Arqueológico Nacional. El resto de elementos, con excepción del hierro, o no se detectan o aparecen con valores inferiores al $0,1 \%$ en pocos ejemplares. El hacha de Mieres se separa de esta tendencia. Además de arsénico tiene un contenido muy elevado de antimonio (2\%) y alto de plata $(0,36 \%)$. En las dos hachas de Cerrocuquillo el plomo y el antimonio se detectan en valores entre el $0,1 \%$ y $0,2 \%$. La presencia de un $0,25 \%$ Sn en el hacha $\mathrm{n}^{\mathrm{o}} 1$ de Mondouzil y de $0,2 \% \mathrm{Sb}$ en el hacha $\mathrm{n}^{\circ} 2$ (Gomez 1998) indican coladas diferentes para cada una de estas hachas francesas.

A título comparativo comentamos la composición de las hachas de los depósitos de Asiego y Torreorgaz, también de cobre con arsénico. Los valores son más elevados en las hachas de Asiego (Reguera 2015) analizadas mediante LA-MC-ICP-MS, todas superan el $2,5 \%$ alcanzado valores máximos del $6 \%$, frente a valores de 1-2\% As de Torreorgaz (Rovira et al. 1997: 132). Ninguno de los otros elementos detectados en estos metales supera el $0,1 \%$. Estas composiciones con arsénico y bajas impurezas de otros elementos es la más frecuente en el metal del Calcolítico y Bronce Antiguo en la mayor parte de la península ibérica, antes de que se introduzca la aleación con estaño.

\section{LOS DEPÓSITOS DE HACHAS PLANAS}

Por el momento los depósitos con más de dos ejemplares de hachas planas anchas son cuatro: el de Valchica con unas veinte, el de Cañada de las Cañas en el que se mencionan trece hachas, el de Yunclillos con siete y el de Estepa con seis. Los de Valchica y Cañada de las Cañas han perdido ejemplares y las noticias sobre el número original de piezas son algo ambiguas. En cambio parece seguro que el depósito de Yunclillos tenía las siete hachas estudiadas. En cuanto a los depósitos de hachas planas grandes, solo conocemos los casos de Asiego con catorce ejemplares y Torreorgaz con siete piezas. Todos estos depósitos se caracterizan por tener ejemplares completos con predominio de un 


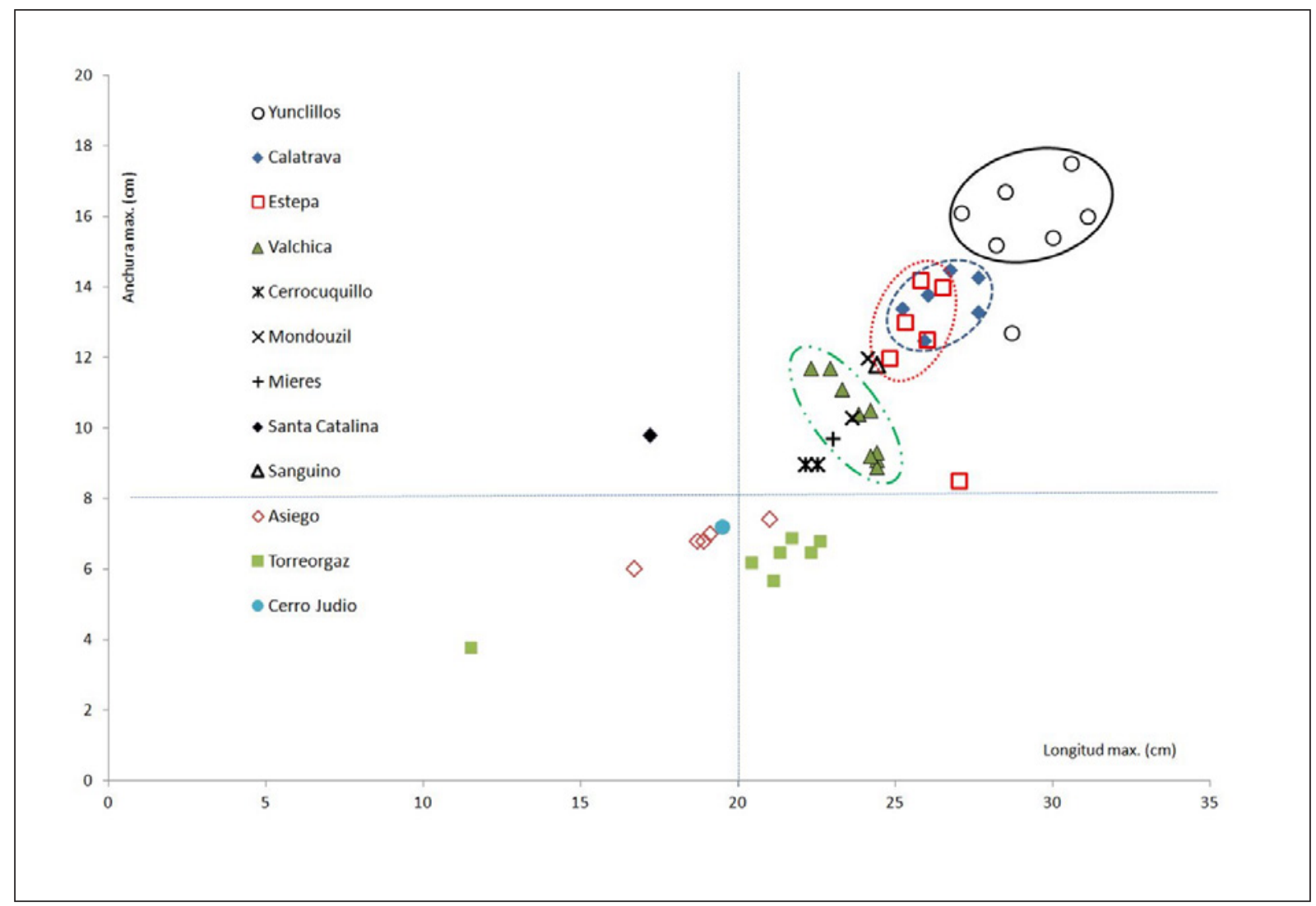

Figura 12. Comparación de las medidas (longitud y anchura máximas) de las hachas planas anchas, de los depósitos de hachas planas y otras hachas mencionadas en el texto.

tipo específico de hacha, a diferencia del depósito de Espite donde había piezas rotas y completas de distintos tamaños.

Los depósitos de Estepa y Yunclillos muestran un cierto orden en la colocación de las hachas por las huellas identificadas en las pátinas. Como en ninguno de los seis citados se menciona la existencia de contenedores, debemos asumir que eran orgánicos o que no los hubo y, en ese caso, las hachas se ocultaron en simples hoyos en la tierra. Tampoco se alude a elementos en piedra o a una cubrición del depósito.

El lugar elegido para ocultar los depósitos de Yunclillos y Valchica carece de rasgos topográficos destacados. Son campos llanos de carácter agrícola. La localización del depósito de Cañadas de las Cañas en un llano a la falda de una sierra es menos clara a ese respecto. En sus proximidades y en las del conjunto de Yunclillos se ha identificado un poblamiento de la Edad del Bronce (entre 800 y 1000 m) (fig. 6), dato que puede ampliarse al hallazgo de las dos hachas de Cerrocuquillo.
Estos depósitos serían definibles como monotipo (hacha plana) si no tuviéramos en cuenta la presencia de un objeto formalmente diferenciado. En Yunclillos es el hacha $n^{\circ} 1$. Su configuración es la más típica de un hacha con perfil trapezoidal por sus bordes rectos, que contrastan con los perfiles más sinuosos y el filo con mayor desarrollo curvo de las otras seis. En Estepa, la pieza n ${ }^{\circ} 498$ es notablemente más estrecha que las otras y tiende a la sección de un cincel (fig. 4). Por último, si aceptamos la pertenencia del hacha del Museo de San Isidro al depósito de las Cañadas de Calatrava, rasgos de la misma como el filo romo y las huellas del martillado en su superficie la asemejan a la pieza de Yunclillos, distinguiéndola del resto. La pérdida de más de la mitad de las hachas de Valchica nos impide saber si alguna tuvo un carácter singular. Lo creemos poco probable porque casi siempre estos objetos, al atraer más atención, se preservan más fácilmente que los objetos repetidos. En Torreorgaz un hacha presenta menores dimensiones (Monteagudo 1977: $\mathrm{n}^{\circ} 52$ ) que las demás, por el contrario el depósito de hachas de Asiego es monotipo sin excepción. 
Merece la pena mencionar otro depósito homogéneo con un objeto diferente. Se trata de Gamonedo, pero en este caso el objeto principal son los diez lingotes de cobre y se incorpora un hacha plana (Blas 1979-80).

\section{VALORACIONES CRONOLÓGICAS}

Como se comentaba en la introducción, la cronología propuesta para los depósitos de hachas planas es muy diversa. Resulta complicado, en particular, fechar la variante ancha y delgada, dada la falta de contextos y material asociado. Creemos desacertada la propuesta de Fernández Gómez $(2003,2004)$ de situar las hachas de Estepa en el Bronce Final a partir de la posible aparición de una pieza en una tumba orientalizante en Carmona (Sevilla). La referencia para la comparación es el ejemplar no 355 de Monteagudo (1977), procedente de la necrópolis de El Judío, que mide 195 x $72 \mathrm{~mm}$, sin datos del grosor. Según Torres (1999: 74) se ignora el contexto de aparición de esta hacha en la necrópolis, por lo que no necesariamente pertenece al ajuar de una tumba. Tampoco podemos paralelizar este ejemplar con las piezas de Estepa, más grandes y sobre todo finas. Por sus dimensiones se asemeja más a las hachas de Asiego (fig. 12). La aparición de piezas prehistóricas en contextos más modernos es esporádica, siendo el caso más citado la punta Palmela hallada en el depósito del Bronce Final de Padilla de Abajo (Burgos) (Fernández-Manzano 1986).

El resto de autores se inclina por encuadrar estas hachas planas de gran formato en momentos que podrían iniciarse en un Calcolítico precampaniforme (Brandherm 2007), vincularlas al Campaniforme según Klassen et al. (2007) o a la segunda mitad del III milenio cal AC según Roussot-Laroque (1997). Para Blas (1999: 51, 2011) el conjunto de Asiego debería pertenecer al Bronce Inicial, con fechas de entre 2200-1700 cal AC. Finalmente Quero Castro (2006) clasifica el hacha del Museo de San Isidro, asignable al conjunto de Cañada de las Cañas, en el Bronce Medio.

Ninguno de los nuevos hallazgos ofrece anclajes precisos, pero la metalurgia precampaniforme en la península ibérica presenta un desarrollo limitado con presencia de punzones y sin hachas planas, a diferencia de lo que ocurre en Europa central y oriental, que sirve a Branderhm (2007) como referente para su propuesta. Al mismo tiempo, este autor sugiere que podrían haberse desarrollado durante el Calcolítico, pero que no alcanzaron el Bronce Inicial por su ausencia en conjuntos cerrados con vinculación al Campaniforme. De manera opuesta, tanto Klassen et al. (2007) como Roussot Larroque (1997) se inclinan a fecharlas en la segunda mitad del III milenio cal AC, con una probable vinculación con el Campaniforme que justificaría la importación de las piezas francesas desde la península ibérica.

De aceptar la vinculación del depósito de Cañada de las Cañas (Pozuelo de Calatrava) con el poblado cercano, su cronología nos llevaría al Bronce Antiguo o Pleno. En cambio, las piezas de Cerrocuquillo solo pueden vincularse a la ocupación del Calcolítico/Bronce Antiguo descrita (Baquedano et al. 2010). Pero este periodo en el que se desarrolla el Campaniforme perdura hasta bien entrado el II milenio cal AC (Balsera y Díaz del Río 2014) en Madrid. Tenemos un contexto similar en la calle Trabajadores 14-18 de Valencina de la Concepción. Allí aparecieron tres hachas grandes. A falta de dataciones radiocarbónicas, el contexto de la ue51, la más moderna del sector central, podría pertenecer a la transición al II milenio cal AC (López Aldana y Pajuelo 2013).

A estos elementos podemos añadir la cronología atribuida a la tumba argárica de Santa Catalina, donde apareció el hacha plana ancha y fina que representa la misma tipología con menores dimensiones. No hay datación absoluta, pero se acepta que hacia el $1800 \mathrm{cal}$ AC aparecen las tumbas masculinas con la asociación de hacha plana y cuchillo (Lull et al. 2011: 388) como sería este caso.

Nuestra propuesta es fechar estos depósitos y la tipología de estas hachas en un momento inicial del Bronce Antiguo, entre los últimos siglos del III milenio cal AC y el primer cuarto del II milenio cal AC. En este periodo todavía se convive con la cerámica campaniforme en el centro peninsular. Esta franja cronológica justifica también que el metal de estas hachas sea siempre cobre o cobre arsenicado, sin que haya producciones de bronce.

\section{CONCLUSIONES}

La revisión de los depósitos y hallazgos individuales de hachas planas anchas permite una nueva lectura cronológica del fenómeno. El nuevo hallazgo de Yunclillos, una mejor valoración del de Estepa, así como la información proporcionada por Cerrocuquillo y el contexto del depósito de Cañada de las Cañas permite encuadrar este registro, con el de los depósitos de Torre Orgaz y Asiego, en la transición del III al II mileno cal AC. Se consolida así la amplia distribución geográfica de la deposición de metales en la península ibérica (fig. 1), fenómeno del que, a día 
de hoy, solo queda excluido el Sureste. La razón parece estar en las características socio-culturales diferenciales de la cultura de El Argar, allí desarrollada (Brandherm 2007).

Los ejemplares que integran cada depósito tienen variaciones formales que marcan su individualidad y apuntan a la ausencia de moldes o matrices en soportes estables. Sin embargo cada depósito mantiene una coherencia interna en las dimensiones de las hachas cuando se compara con el resto (fig. 12). Así, las piezas de mayor tamaño corresponden a Yunclillos y las más pequeñas a Valchica, mientras que Estepa y Campo de Calatrava, con dimensiones intermedias, son más similares entre sí. Las hachas de los depósitos de Asiego y Torreorgaz tienen menor longitud y anchura (y mayor grosor) que las hachas planas anchas, pero también se diferencian entre sí.

Una interpretación de tipo social de estos hallazgos nos debiera llevar a examinar cuestiones como la producción y el transporte, el comercio y el intercambio de este tipo de bienes de prestigio y, lo que es más importante, la finalidad última del objeto. Sus dimensiones, algunos rasgos formales y sobre todo la gran cantidad de metal consumido en su manufactura pueden cuestionar su funcionalidad como herramientas, siendo el lingote una función alternativa. Sin embargo, una precisa argumentación a favor y en contra de su funcionalidad requiere de un mayor espacio del ahora disponible, al igual que los motivos que están detrás de la deposición/ocultación del metal. La característica común de su deposición fuera de los lugares de hábitat y de que, en general, sean piezas completas en buen estado de conservación (pero véase arriba la anormalidad de algunas hachas de Yunclillos a este respecto) son rasgos que habrá que tener en cuenta cuando se plantee su finalidad o intencionalidad.

Coincidimos con Brandherm (2007: 190) en que estas deposiciones de hachas, o de acumulación de metal, si incluimos el depósito de Gamonedo, no responden a un único modelo interpretativo. Nuestro objetivo ha sido intentar mejorar el encuadre cronológico del fenómeno de los depósitos no funerarios de hachas, señalando que quizás su inicio y las causas que llevan a realizarlas corresponden a momentos más avanzados de lo que algunos autores habían sugerido. Su aparición en Francia es también un indicador de las relaciones culturales durante la Edad del Bronce y de la posible movilidad de los metales.

\section{Agradecimientos}

Al Museo Arqueológico de Sevilla y a Mark Hunt por la información y las fotos del depósito de Estepa.
A Eduardo Galán por sus orientaciones y datos sobre los materiales del Museo Arqueológico Nacional. A Oscar García-Vuelta por la documentación gráfica del depósito de Yunclillos. El conocimiento del depósito tuvo lugar durante los trabajos realizados dentro del proyecto "Estudio de las comunidades de la Edad del Bronce en el término municipal de Bargas (Toledo)" financiado por la Excma. Diputación de Toledo. La investigación presentada en este artículo se encuadra dentro de las actividades del proyecto del Plan Nacional subvencionado por el Ministerio de Economía, Industria y Competitividad, Programa estatal de investigación, desarrollo e innovación orientada a los retos de la sociedad (HAR2017-82685-R): "Metal y ámbar: modelos de circulación de materias primas en la Prehistoria Reciente de la península ibérica".

\section{BIBLIOGRAFÍA}

Balsera, V. y Díaz del Río, P. (2014): "Haciendo tiempo. La cronología absoluta de la Prehistoria reciente madrileña”, en Actas de las novenas jornadas de Patrimonio Arqueológico de la Comunidad de Madrid (Madrid 2012). Boletín Oficial de la Comunidad de Madrid: 35-50. Madrid. Consejería de Cultura, Turismo y Deporte, Comunidad de Madrid.

Baquedano Beltrán, I.; Torija López, A. y Cruz Mateos, M. (2010): “Algunos apuntes sobre las excavaciones en curso del yacimiento de Cerrocuquillo (Villaluenga de La Sagra, Toledo), en A. Madrigal Belinchón y M. Perlines Benito (eds.), Actas de las II Jornadas de Arqueología de Castilla La Mancha Vol I: 116-156. Toledo (2007), Toledo, Diputación de Toledo, Junta de Castilla-La Mancha.

Bardavíu, V. (1922): "Un depósito de hachas de cobre". Boletín del Museo Provincial de Bellas Artes de Zaragoza 8: 10-11.

Blanco de la Rubia, I. (1983):"El Castillejo de Acebuchal: un yacimiento de la Edad del Bronce (Pozuelo de Calatrava, Ciudad Real)", en Crónica del XVI Congreso Arqueológico Nacional: 359-370. Cartagena (1982), Zaragoza, Universidad de Zaragoza.

Blas Cortina, M.A. de (1999): "Asturias y Cantabria", en G. Delibes de Castro e I. Montero Ruiz (eds.), Las primeras etapas metalúrgicas en la Península Ibérica. II. Estudios regionales: 41-62. Madrid, Instituto Universitario Ortega $y$ Gasset.

Blas Cortina, M.A. de (1979-1980): “El depósito de materiales de la Edad del Bronce de Gamonedo (Asturias)". Zephyrus 30-31: 268-276. 
Blas Cortina, M.A. de (2011): "De la caverna al lugar fortificado: una mirada a la Edad del Bronce en el territorio Astur-Cántabro". Quaderns de Prehistòria i Arqueologia de Castelló 29: 105-134.

Brandherm, D. (2007): “Sobre el origen del fenómeno de los depósitos en la Península Ibérica: ocultaciones de objetos metálicos de los inicios de la Edad del Bronce", en J. Celis, G. Delibes de Castro, J. Fernández Manzano y L. Grau Lobo (eds.), El hallazgo leonés de Valdevimbre y los depósitos del Bronce Final Atlántico en la Península Ibérica: 177-193. Estudios y Catálogos 17. León, Junta de Castilla y León y Diputación de León.

Fernández Gómez, F. (2003): Phiale. Sea routes...From Sidon to Huelva. Interconnections in the Mediterranean 16th-6th centuries B.C. Atenas, Museum of Cycladic Art.

Fernández Gómez, F. (2004): Arqueología del Valle del Guadalquivir: de la Prehistoria a Roma. Vitoria, Caja Vital Kutxa.

Fernández Manzano, J. (1986): Bronce Final en la Meseta Norte: el utillaje metálico. Monografias, Investigaciones Arqueológicas en Castilla y León. Valladolid, Junta de Castilla y León.

Gener, M.; Rovira-Llorens, S.; Montero-Ruiz, I. y Rodríguez-Vinceiro, F. (2009): “Technological evolution of the cutting edges in prehistoric axes and palstaves", en J.F. Moreau, R. Auger, J. Chabot y A. Herzog (eds.): Proceedings ISA 2006. 36th International Symposium on Archaeometry: 179-185. Cahiers d'archéologie du CELAT 25. Série archéométrie 7. Quebec City, Canada (2006), Quebec, l'Université Laval-CELAT, Centre de recherche Cultures - Arts - Sociétés.

Gomez, J. (1998): “Au sujet de l'article de Julia Roussot-Larroque (1997) 'Dépôt de haches plates géantes à Bégadan (Gironde)". Bulletin de la Société préhistorique française 95 (1): 19-120.

Harding, A. (2003): Sociedades europeas en la Edad del Bronce. Barcelona, Ariel Prehistoria.

Junghans, S.; Sangmeister, E. y Schröder, M. (1968): Kupfer und Bronze in der Frühen Metallzeit Europas. Katalog der Analysen Nr. 985-10040. Studien zu den Anfängen der Metallurgie 2,3. Berlín, Mann.

Klassen, L.; Pétrequin, P. y Grut, H. (2007): "Haches plates en cuivre dans le Jura français. Transferts à longue distance de biens socialement valorisés pendant les IV et III $^{\mathrm{e}}$ millénaires". Bulletin de la Société préhistorique française 104(1): 101-124.

López Aldana, P. y Pajuelo Pando, A. (2013): "La secuencia ocupacional durante el III milenio en Calle
14-18 (Valencia de la Concepción, Sevilla)", en L. García Sanjuán, J. M. Vargas Jiménez, V. Hurtado Pérez, T. Ruiz Moreno y R. Cruz-Auñón Briones (eds.), El asentamiento prehistórico de Valencina de la Concepción (Sevilla): investigación y tutela en el 150 aniversario del descubrimiento de La Pastora: 157-169. Serie Historia y Geografía 243. Sevilla, Universidad de Sevilla.

Lull, V. (1983): La cultura de El Argar. Madrid, Akal. Lull, V.; Micó, R.; Rihuete, C. y Risch, R. (2011): "El Argar and the beginning of class society in the Western Mediterranean”, en S. Hansen y J. Müller (eds.), Sozialarchäologische Perspektiven: Gesellschaftlicher Wandel 5000-1500 v.Chr. zwischen Atlantik und Kaukasus: 381-414. Archäologie in Eurasien 24. Berlin, Verlag Phillip Von Zabern.

Monteagudo, L. (1977): Die Beile auf der Iberischen Halbinsel, Prähistorische Bronzefunde, Abteilung IX, Bd. 6. München, C.H. Beck'sche Verlagsbuchhandlung.

Muñoz Amilibia, A.M. (1984-85): “Una sepultura argárica de El Verdolay (Murcia)". Cuadernos de Prehistoria y Arqueología Universidad Autónoma de Madrid 11-12: 133-142.

Needham, S.P.; Lawson, A.J. y Green, H.S. (1985): British Bronze Age Metalwork. A1-6 Early Bronze Age Hoards. London. British Museum.

Quero Castro, S. (2006): "Cat. N 7 Hacha plana", en El legado Sáez Martín a los museos municipales de Madrid: 56-57. Madrid, Museo de San Isidro, Ayuntamiento de Madrid.

Reguera, A. (2015): Desarrollo y aplicación de metodologías de medida de relaciones isotópicas en muestras solidas medidas mediante ablación láser acoplada a espectrometría de masas. Tesis doctoral, Universidad de Oviedo. http://hdl.handle. net/10651/37468 (17/3/2018).

Rovira, S. y Montero Ruiz, I. (2018): "Proyecto Arqueometalurgia de la Península Ibérica (19822017)". Trabajos de Prehistoria 75(2): 223-247. https://doi.org/10.3989/tp.2018.12213

Rovira, S.; Montero, I. y Consuegra, S. (1997): Las primeras etapas metalúrgicas en la Península Ibérica. I Análisis de materiales. Madrid, Instituto Universitario Ortega y Gasset.

Roussot-Larroque, J. (1997): "Dépôt de haches plates géantes de Bégadan (Gironde). Bulletin de la Société préhistorique française 94: 573-580.

Ruiz-Taboada, A. y Montero, I. (2000): "The pattern of use of stone and copper in Central Spain during the 
Bronze Age". European Journal of Archaeology, 3(3): 350-369.

Torres Ortiz, M. (1999): Sociedad y mundo funerario en Tartessos. Madrid, Real Academia de la Historia.

Uriarte González, A.; Pereira Sieso, J.; Montero Ruiz, I.; Martínez Navarrete, M.I. y Carrobles Santos, J. (2011): "La Edad del Bronce en el Bajo Guadarrama (Bargas, Toledo): trabajos de prospección arqueológica 2005-2007”, en V. Mayoral Herrera y S. Celestino Pérez (eds.), Tecnologías de Información geográfica y análisis arqueológico del territorio. Actas del V Simposio Internacional de Arqueología de Mérida: 69-77. Anejos del Archivo Español de Arqueología LIX. Mérida, Instituto de Arqueología Mérida, CSIC -Junta de ExtremaduraConsorcio de Mérida. 
